\title{
Analysis of thermal behaviors of hot surface glass pane subjects to down-flowing water film via smoothed particle hydrodynamics
}

\author{
D.A. Abdoh ${ }^{1}$, A.S. Ademiloye ${ }^{2}$, K.M. Liew ${ }^{1, *}$ \\ ${ }^{1}$ Department of Architecture and Civil Engineering, City University of Hong Kong, Kowloon, \\ Hong Kong, China \\ ${ }^{2}$ Zienkiewicz Centre for Computational Engineering, College of Engineering, Swansea University, \\ Bay Campus, Swansea, SA1 8EN, United Kingdom
}

\begin{abstract}
Glass cooling using water film depends on several parameters such as heat flux, downflowing velocity, and thickness of water film. The efficiency of glass protection with water film can be significantly enhanced through a proper combination of the fire and water film parameters. This study aims to present an in-depth investigation into the influence of the heat flux, down-flowing velocity and thickness of water film parameters on the thermal behavior of glass panes during a fire and to propose new guidelines to enhance the efficiency of the water film glass protection system. Smoothed particle hydrodynamics (SPH) method is used here to simulate glass cooling with a down-flowing water film. Based on several SPH simulation scenarios of glass cooling at a different fire and water film working conditions, new empirical equations are derived to describe the effects of heat flux, down-flowing velocity, and thickness of water film on the temperature drop in glass and water film. Furthermore, these empirical equations were employed to study the evaporation of water film and to compare the efficiency of the cooling mechanism with different down-flowing velocity and thickness of water film. The simulation results confirm that increasing down-flowing velocity is more efficient in glass cooling than increasing water film thickness.
\end{abstract}

Keywords: Glass cooling; Fire; Water film; Smoothed Particle Hydrodynamics (SPH); Thermal analysis; Temperature distribution

\footnotetext{
* Corresponding author.

Email address: kmliew@ cityu.edu.hk (K.M. Liew)
} 


\section{Introduction}

Water is widely used in fire extinguishing [1], particularly water film is applied on glass to protect it from breakage since glass breakage plays a vital role in fire spreading [2]. The efficiency of water film glass protection system depends on many parameters such as heat flux (fire severity), down-flowing velocity and thickness of water film. Several researchers have carried out numerous experiments on the thermal behavior of water film during fire outbreaks in an attempt to clearly understand the role of these aforementioned parameters on glass cooling mechanism by water film. For instance, experimental research works were conducted to examine the radiative heat transfer from fire source to water film $[3,4]$. Also, fire tests of wall curtains with a water film were performed to study the efficiency of water film system, it was found that water film is more efficient for wall curtain protection than the fireproofing material [5].

The heat transfer mechanism in glass during fire with water film was examined experimentally [6] and it was revealed that water film is more efficient in glass protection than sprinklers. However, the water film release time is a vital factor in glass protection. It has been reported that an early release of water film is more productive in preventing glass breakage and fallout $[7,8]$. Down-flowing velocity and thickness of water film are considered important parameters in determining the efficiency of water film system, for instance, it was found that water film with an average thickness of 1.5 $\mathrm{mm}$ flowing on glass with a down-flowing velocity of about $0.7 \mathrm{~m} / \mathrm{s}$ is capable of protecting the glass from breakage when exposed to a certain fire intensity [9].

Experiments were also conducted to examine the effects of the cooling process in many applications like in the glass solar system [10]. However, mesh-based methods have also been employed to understand glass cooling mechanism numerically in a bid to overcome some known limitations of experimental studies. For instance, the finite 
volume method was employed to study the heat transfer characteristics of the cooling system in an industrial glass tempering unit [11]. Moreover, heat transfer through water film and glass pane were examined using the finite difference method [12].

Recently, the evaporation process gained great interest in numerical research due to its significant impact on cooling efficiency. Heat and mass transfer characteristics for laminar air flow inside vertical plate channels during cooling process with falling water film evaporation were studied using finite volume method $[13,14]$, where empirical correlations were derived to calculate the Nusselt and Sherwood numbers taking into consideration the effects of several parameters [14]. On the other hand, the mathematical Trefftz method was employed to examine the heat transfer coefficient for Inconel during spray cooling [15].

Nowadays, meshfree methods are increasingly utilized to avoid the deficiency caused by the mesh distortion in mesh-based methods particularly for problems involving large deformation [16,17] and continuous flowing fluid [18]. Smoothed particle hydrodynamics (SPH) method is considered one of the most traditional meshfree methods [19-24]. SPH method was used to analyze the natural convection in a horizontal cylindrical annulus for different values of Rayleigh and Prandtl numbers [25]. Moreover, different cases of heat transfer have been numerically studied using the SPH method [26-28]. In this present contribution, the SPH method is utilized to simulate the glass cooling by water film and to derive new empirical equations that relate the temperature distribution of glass with different parameters. Furthermore, the evaporation of water film is carefully examined and recommendations are proposed to enhance the efficiency of the water film glass protection system. 


\section{Problem statement}

The main configuration of the problem consists of a glass pane $\left(0.6 \times 0.6 \times\left(6 \times 10^{-3}\right)\right.$ $\mathrm{m}^{3}$ ) fixed at the top of the water recovery tank. The fire pool is located near the glass pane to generate the heat source. Thirty-five (35) points are defined in the glass pane section as shown in Fig. 1(a), where the temperature values at some of these points are used in the validation stage and in describing the new applications of our SPH model. Previous experimental temperature measurements and Ansys-fluent software temperature results at the exposed surface of the glass (P3) are compared with our numerical model. Also, CFD-Autodesk and Ansys-CFX are used to verify the temperature values at $\mathrm{P} 3, \mathrm{P} 18$ and $\mathrm{P} 33$ points [29].

In addition to the geometry of the glass pane, the following parameters were considered in the design of our proposed mathematical framework: the maximum heat flux $(M H F)$, the velocity of down-flowing water film $(V)$, released time and thickness of water film (WFT). Fig. 1(b) shows the heat flux variation with time used in the verification stage [7], where the maximum heat flux equals $15 \mathrm{~kW} \cdot \mathrm{m}^{-2}$. Additional four heat flux variations with time were created by multiplying the experimental heat flux variation with $1.2\left(M H F=18 \mathrm{~kW} \cdot \mathrm{m}^{-2}\right), 1.4\left(M H F=21 \mathrm{~kW} \cdot \mathrm{m}^{-2}\right), 0.8\left(M H F=12 \mathrm{~kW} \cdot \mathrm{m}^{-}\right.$ $\left.{ }^{2}\right)$ and $0.6\left(M H F=9 \mathrm{~kW} \cdot \mathrm{m}^{-2}\right)$. These heat flux curves as shown in Fig. 1(b) will also be used in our empirical equations' derivations. The down-flowing velocity used in the derivation of the new empirical equations ranges from $0.3 \mathrm{~m} / \mathrm{s}$ to $1 \mathrm{~m} / \mathrm{s}$. Three values of water film thicknesses $(W F T), 0.5 \times 10^{-3} \mathrm{~m}, 0.7 \times 10^{-3} \mathrm{~m}$, and $0.8 \times 10^{-3} \mathrm{~m}$, were also considered. The new empirical equations proposed in our present contribution can be employed to obtain the complex relationship between glass and water film temperatures and the aforementioned fire and water film parameters. Table 1 summarizes the material properties used in our numerical simulations. 


\section{Numerical method and model validation}

\subsection{Governing equation and heat transfer mode}

Heat energy is transferred in our numerical model through radiation, convection, and conduction. The heat transfer equation governing the heat transfer mechanism is shown below:

$$
\frac{\partial T}{\partial t}=\frac{1}{\rho C_{p}}\left(k\left(\frac{\partial^{2} T}{\partial x^{2}}+\frac{\partial^{2} T}{\partial y^{2}}\right)+Q(H F)\right)
$$

where $T$ is the temperature, $\rho$ is the density, $C_{p}$ is the specific heat capacity, $k$ is the thermal conductivity and $Q(H F)$ is the heat flux value. Heat energy is transferred from fire to exposed layer of water film or glass by radiation, where Eq. (1) is utilized to calculate the temperature change by substituting the related material properties. However, $Q(H F)$ equals zero when heat is transferred between water film and glass particles by convection or when heat is transferred by conduction within the same glass or water film particles as depicted in Fig. 2. Accordingly, Eq. (1) is solved multiple times with different material parameters and boundary conditions to capture the total heat transfer process at each time step of glass cooling simulation. More details can be found in our previous work [29].

\subsection{SPH solution}

SPH method is employed here to simulate the heat transfer from fire to glass through water film as shown in Fig. 2. The domain of interest is divided into a finite number of particles, where the unknown field variable is approximated according to the SPH formula shown in Eq. (2):

$$
F\left(r_{i}\right)=\sum_{j=1}^{N} \frac{m_{j}}{\rho_{j}} F\left(r_{j}\right) W_{i j}(R, h)
$$


where $F\left(r_{i}\right)$ and $F\left(r_{j}\right)$ are the unknown variables, such as the temperature, for the origin and nearby particles at positions $r_{i}$ and $r_{j}$, respectively, $m_{j}$ and $\rho_{j}$ are the mass and density of nearby particles $j$, respectively, and $N$ is the total number of nearby particles $j$ within the support kernel domain $(\mathrm{R}) . W_{i j}(R, h)$ is the kernel smoothing function which is used as an interpolation function, where piecewise cubic smoothing kernel function in 2D [26] is used here as follows:

$W_{i j}(R, h)=\frac{15}{7 \pi h^{2}}\left\{\begin{array}{cr}\frac{2}{3}-\frac{r_{i j}^{2}}{h}+\frac{1}{2} \frac{r_{i j}{ }^{3}}{h}, & 0 \leq \frac{r_{i j}}{h}<1 \\ \frac{1}{6}\left(2-\frac{r_{i j}}{h}\right)^{3}, & 1 \leq \frac{r_{i j}}{h} \leq 2 \\ 0, & 2 \leq \frac{r_{i j}}{h}\end{array}\right.$

where $r_{i j}$ is the distance between the main particle $i$ and nearby particle $j$. The second derivatives are replaced with algebraic equations as shown in Eq. (4):

$$
\nabla^{2} F\left(r_{i}\right)=\sum_{j=1}^{N} \frac{m_{j}}{\rho_{j}} F\left(r_{j}\right) \nabla_{i j}^{2} W_{i j}(R, h)
$$

where $\nabla^{2} F\left(r_{i}\right)$ is the second derivative of the function variable, $\nabla_{i j}{ }^{2} W_{i j}(R, h)$ is the second derivative of the smoothing kernel function. The discretized form of the heat transfer equation is formulated by replacing the second derivatives in the heat transfer equation (Eq. (1)) with Eq. (4), the result is shown in Eq. (5) [29]:

$$
\begin{aligned}
T_{i(t+1)}=\frac{1}{\rho C_{p}} & \left(\sum_{j=1}^{N}\left(\alpha \frac{m_{j}}{\rho_{j}} T_{j}\left(\frac{\partial^{2}}{\partial x^{2}} W_{i j}(R, h)+\frac{\partial^{2}}{\partial y^{2}} W_{i j}(R, h)\right)\right)+Q\right) \Delta t \\
& +T_{i(t)}
\end{aligned}
$$

where:

$$
\frac{\partial^{2} W_{i j}(R, h)}{\partial x}=\frac{15}{7 \pi h^{2}}\left\{\begin{array}{l}
\left(\frac{-2}{h^{2}}\right)+\left(\frac{3}{2 r_{i j} h^{3}}\left(x_{i}-x_{j}\right)^{2}\right)+\left(\frac{3 r_{i j}}{2 h^{3}}\right), 0 \leq R<1 \\
\left(\frac{1}{3 h^{2}}\right)+\left(\frac{2}{3 r_{i j}{ }^{3} h}\left(x_{i}-x_{j}\right)^{2}\right)-\left(\frac{2}{3 h r_{i j}}\right), 1 \leq R \leq 2
\end{array}\right.
$$




$$
\frac{\partial^{2} W_{i j}(R, h)}{\partial y}=\frac{15}{7 \pi h^{2}}\left\{\begin{array}{c}
\left(\frac{-2}{h^{2}}\right)+\left(\frac{3}{2 r_{i j} h^{3}}\left(y_{i}-y_{j}\right)^{2}\right)+\left(\frac{3 r_{i j}}{2 h^{3}}\right), 0 \leq R<1 \\
\left(\frac{1}{3 h^{2}}\right)+\left(\frac{2}{3 r_{i j} h^{3}}\left(y_{i}-y_{j}\right)^{2}\right)-\left(\frac{2}{3 h r_{i j}}\right), 1 \leq R \leq 2
\end{array}\right.
$$

$T_{j}$ is the temperature of particles $j$ in the current time step. $T_{i(t)}$ and $T_{i(t+1)}$ are the temperature values for particle $i$ at current and next time steps, respectively, and $\Delta t$ is the time step in seconds.

\subsection{Model validation}

Down-flowing velocity and thickness of water film equal to $0.645 \mathrm{~m} / \mathrm{s}$ and $0.5 \times 10^{-3}$ $\mathrm{m}$, respectively, are considered in the verification stage. Previous experimental temperature measurements at the exposed surface of the glass are compared with our SPH model and Ansys-fluent. Fig. 3 shows the temperature variation with time at point P3 on the glass after applying water film using our SPH numerical model, experimental measurements and Ansys-fluent [29]. It can be seen that there are some differences between the experimental and the numerical results after 90 seconds, this is due to the effects of water film flow on thermocouples sheets fixed at the exposed surface in the experiment but despite that, all the temperature variation curves are well-aligned particularly at the main cooling stage which occurs before 90 seconds (rapid cooling occurs at the exposed surface), thus indicating the efficiency of our numerical model. Furthermore, we performed extended verification tests by comparing the temperature variations produced by our SPH model with Ansys-CFX and Autodesk-CFD results at P3, P18 and P33 points on the glass as shown in Fig. 4 [29]. 


\section{Results and discussions}

\subsection{General trends}

In order to understand the general trends and relationships between glass temperature distribution and varying fire and water film parameters, our SPH model was employed to compute temperature variations at points $\mathrm{P} 8, \mathrm{P} 17, \mathrm{P} 19$ and $\mathrm{P} 28$ with different heat flux, down-flowing velocity, and thickness of water film as shown in Figs. 5 to 7 . When the down-flowing velocity $(V)$ of the water film increases, the overall glass temperature drop increases more sharply due to the increase in heat transfer rate. For instance, the temperature at point $\mathrm{P} 19$ drops from $43.5^{\circ} \mathrm{C}$ to $37^{\circ} \mathrm{C}$ and $30^{\circ} \mathrm{C}$ within 75 seconds after water film release when down-flowing velocity equals $0.4 \mathrm{~m} / \mathrm{s}$ and $0.8 \mathrm{~m} / \mathrm{s}$, respectively, as shown in Fig. 5(a) and Fig. 5(b). On the other hand, the glass temperature drop increases when heat flux increases owing to the much higher glass temperature prior to the release of the water film. When $M H F$ equals $9 \mathrm{~kW} \cdot \mathrm{m}^{-2}$, the temperature at point $\mathrm{P} 17$ decreases from $43.5^{\circ} \mathrm{C}$ to $26.5^{\circ} \mathrm{C}$ (temperature drop of about $17^{\circ} \mathrm{C}$ ) while it decreases from $69^{\circ} \mathrm{C}$ to $29^{\circ} \mathrm{C}$ (temperature drop of about $40^{\circ} \mathrm{C}$ ) when $M H F$ equals $21 \mathrm{~kW} \cdot \mathrm{m}^{-2}$ as shown in Fig. 6(b) and Fig. 6(d), respectively.

The effects of increasing water film thickness on temperature drop were also well captured by our SPH model. For example, when water film thickness (WFT) increases from $0.5 \times 10^{-3}$ to $0.8 \times 10^{-3} \mathrm{~m}$, the temperature at Point P8 (140 s) decreases by about $10.5 \%$ (from $33.5^{\circ} \mathrm{C}$ to $30^{\circ} \mathrm{C}$ ) as shown in Fig. 5(a) and Fig. 7(a), respectively. The temperature variations between different point locations are shown clearly in Figs. 5 to 7. Based on the temperature variations at points P17 and P19, we observed that the overall glass temperature drop decreases from the top of the glass to the bottom (i.e. when $y$-coordinate decreases). It is also noteworthy to mention that the glass temperature prior to the release of the water film decreases across its section (i.e. when 
$x$-coordinate increases), thus the temperature drop after releasing water film is larger at a point near the exposed surface of glass than a farther point with the same $y$ coordinate.

\subsection{Empirical equations}

Based on the observed trends between temperature variation in the glass and different fire and water film parameters, our SPH model was employed to derive new empirical equations that can be used by fire scientists, engineers and researchers to predict glass temperature distribution during a fire outbreak subject to different fire and water film scenarios.

Glass temperature variation with time after applying water film is divided into three main stages. The first stage starts when the temperature of the glass drops sharply following the release of the water film until temperature decrement becomes negligible. In the second stage, the temperature balance between glass and water film occurs after the rapid cooling, accordingly, the change in temperature in this stage is minimal. The third stage takes place when heat flux decreases (fire decaying), glass temperature decreases again until it eventually reaches its initial temperature (before heating).

The most important stage is the first one since the thermal stresses are highest here due to high temperature differences. Therefore, the mathematical equation of the main cooling curve is carefully examined and evaluated whilst taking into consideration several other parameters. The down-flowing velocity of water film $(V)$, glass pane geometry (i.e. $x$ and $y$ coordinates), the thickness of water film, heat flux (MHF) and release time of water film are the independent variables in our mathematical derivation. The temperature drop curve is fitted with a fourth-degree polynomial equation in order to obtain the best possible accuracy as follows:

$$
T(t)=a t^{4}+b t^{3}+c t^{2}+d t+e
$$


To solve for the coefficients - $a, b, c, d$, and $e$, we defined and substituted five (5) time steps and their corresponding temperature values into Eq. (8), the solution is presented in matrix form as follows:

$$
\left(\begin{array}{l}
a \\
b \\
c \\
d \\
e
\end{array}\right)=\left(\begin{array}{lllll}
\mathrm{t}_{1}^{4} & \mathrm{t}_{1}^{3} & \mathrm{t}_{1}^{2} & t_{1} & 1 \\
\mathrm{t}_{2}^{4} & \mathrm{t}_{2}^{3} & \mathrm{t}_{2}^{2} & t_{2} & 1 \\
\mathrm{t}_{3}^{4} & \mathrm{t}_{3}^{3} & \mathrm{t}_{3}^{2} & t_{3} & 1 \\
\mathrm{t}_{4}^{4} & \mathrm{t}_{4}^{3} & \mathrm{t}_{4}^{2} & t_{4} & 1 \\
\mathrm{t}_{5}^{4} & \mathrm{t}_{5}^{3} & \mathrm{t}_{5}^{2} & t_{5} & 1
\end{array}\right)^{-1} \quad\left(\begin{array}{l}
T_{1} \\
T_{2} \\
T_{3} \\
T_{4} \\
T_{5}
\end{array}\right)
$$

where $t_{1}$ is the time when water film is released and $t_{5}$ is the time when the temperature of the glass no longer decreases significantly. The elapsed time between $t_{5}$ and $t_{1}$ is the duration of the main cooling stage, this time difference $\left(t_{5}-t_{1}\right)$ is divided into four additional time steps: $t_{2}=0.15\left(t_{5}-t_{1}\right)+t_{1}, t_{3}=1 / 3\left(t_{5}-t_{1}\right)+t_{1}$ and $t_{4}=$ $2 / 3\left(t_{5}-t_{1}\right)+t_{1} . T_{1}, T_{2}, T_{3}, T_{4}$ and $T_{5}$ are the temperature values corresponding to these $t$ time steps as shown in Fig. 8. Our SPH model was then employed to determine how these time steps and temperature values are related to different fire and water film parameters.

Fig. 8 illustrates the general methodology used to derive the empirical equations. On one hand the dependent variable $(y)$ represents the temperature values $T_{1}, T_{2}, T_{3}$ $, T_{4}, T_{5}$ and cooling time $\left(t_{5}-t_{1}\right)$. On the other hand, the independent variables (fire and water film parameters) are down-flowing velocity $(V), x$-coordinate (location through glass thickness) and maximum heat flux $(M H F)$. Since the dependent variable $(y)$ is evaluated with multiple parameters, our technique in formulating the mathematical relations is to first link only one main parameter to the dependent variable (y). Following this, the other parameters are linked to the main parameter, which in turn, relates the other parameters to the dependent variable $(y)$ as a chain as shown in Fig. 8, where level number reflects the number of stages needed to formulate the final 
shape of empirical equation. For instance, $T_{2}, T_{3}, T_{4}$ and $T_{5}$ variables are linked firstly with down-flowing velocity $(V)$ (main parameter) at each maximum heat flux value $(M H F)$, the relation is found to be polynomial to the third power when plotting these values obtained from the verified SPH model. Then the coefficients of this polynomial equation $\left(a_{3}, b_{3}, c_{3}\right.$ and $\left.d_{3}\right)$ are related to the maximum heat flux value $(M H F)$, the relation is found to be linear. Finally, the linear coefficients $\left(a_{1}\right.$ and $\left.b_{1}\right)$ from the previous relation are related to the $y$-coordinate. It is noteworthy to mention that further derivation details are not presented here in order to concentrate more on the empirical equation's applications.

\subsubsection{Temperature $T_{1}$}

The glass temperature $\left(T_{1}\right)$ prior to the release of the water film depends on the amount of heat flux received by glass particles, thus the water film release time and heat flux intensity $(M H F)$ determine $T_{1}$ value. When the release time is delayed or $M H F$ increases, $T_{1}$ increases, and vice versa. Moreover, the value of $T_{1}$ decreases when the point location moves toward the ambient surface of glass, when $x$-coordinate (through glass thickness) increases, as demonstrated in Section 4.1. The two parameters, $x$ coordinate and $M H F$, are related to the dependent variable $T_{l}$ using the general formula given in Fig. 8. By tracking $T_{1}$ with different $x$-coordinate and $M H F$ values in several SPH simulations, we observed that this relationship is approximately linear which can be expressed as follows (Eq. (10)):

$T_{1}=(-150 x+2.6) M H F+24$

where $T_{l}$ is the temperature at any point in the glass before applying water film in ${ }^{\circ} \mathrm{C}$, $x$ is the $x$-coordinate of the required point in meters, $M H F$ is the maximum heat flux in $\mathrm{kW} \cdot \mathrm{m}^{-2}$. 


\subsubsection{Cooling time period $\left(t_{5}-t_{1}\right)$}

As depicted in Fig. 8, the cooling time period $\left(t_{5}-t_{1}\right)$ depends on $x$-coordinate and down-flowing velocity $(V)$. The glass temperature drops more steeply, and the cooling process takes less time at exposed surfaces than the far one. On the other hand, when down-flowing velocity $(V)$ increases, the temperature drop increases and thus increasing the time needed to reach that lower temperature. Since the cooling time period depends on two parameters, the first one (down-flowing velocity) is related to the cooling time variable while the $x$-coordinate is linked to the down-flowing velocity ( $V$ ) as shown in Fig. 8. Mathematically, the cooling time period is expressed for each water film thickness as follows:

$$
\begin{aligned}
& \left(t_{5}-t_{1}\right)_{\mid\left(W F T=0.5 \times 10^{-3} \mathrm{~m}\right)}=\left(638125 x^{2}+1491 x+16.68\right) \mathrm{V}+\left(-888375 x^{2}+\right. \\
& 12930 x+1.41) \\
& \left(t_{5}-t_{1}\right)_{\mid\left(W F T=0.7 \times 10^{-3} \mathrm{~m}\right)}=\left(718000 x^{2}-458.5 x+21.32\right) \mathrm{V}+ \\
& \left(-810125 x^{2}+13631 x-0.21\right) \\
& \left(t_{5}-t_{1}\right)_{\mid\left(W F T=0.8 \times 10^{-3} \mathrm{~m}\right)}=\left(362250 x^{2}+300 x+20.05\right) V+\left(-581375 x^{2}+\right. \\
& 13375 x+0.56)
\end{aligned}
$$

where $x$ is the $x$-coordinate in meters and $V$ is the down-flowing velocity of water film in $\mathrm{m} / \mathrm{s}$. Finally, if water film thickness increases, cooling time period $\left(t_{5}-t_{1}\right)$ increases because heat transfer through a higher number of water film layers requires more time.

\subsubsection{Temperature values $T_{2}, T_{3}, T_{4}$, and $T_{5}$}

Temperature values $T_{2}, T_{3}, T_{4}$, and $T_{5}$ are related to down-flowing velocity $(V)$, maximum heat flux $(M H F)$ and $y$-coordinate as shown in Fig. 8. The values of temperature, $T_{2}, T_{3}, T_{4}$, and $T_{5}$ decrease when down-flowing velocity or $y$-coordinate increase, however, they increase with an increase in maximum heat flux $(M H F)$. The 
equations that connect the temperature values $T_{2}, T_{3}, T_{4}$, and $T_{5}$ to the relevant parameters are presented below for $0.5 \times 10^{-3} \mathrm{~m}$ water film thickness:

$$
\begin{aligned}
& T_{2 \mid\left(W F T=0.5 \times 10^{-3} \mathrm{~m}\right)}=\left[(-3.7 y-2.34) M H F+\left(262.45 y^{2}-89.22 y+\right.\right. \\
& 10.21)] V^{3}+\left[(2.12 y+7.17) M H F+\left(-352.26 y^{2}+103.24 y-15.67\right)\right] V^{2}+ \\
& {\left[(4.61 y-7.44) M H F+\left(136.65 y^{2}-34.92 y+11.1\right)\right] V+[(-4.1 y+} \\
& \left.4.21) M H F+\left(-15.05 y^{2}+7.03 y+22.085\right)\right] \\
& T_{3 \mid\left(W F T=0.5 \times 10^{-3} \mathrm{~m}\right)}=\left[(-1.4 y-4.42) M H F+\left(192.72 y^{2}-37.26 y+\right.\right. \\
& 0.93)] V^{3}+\left[(-5.11 y+12.97) M H F+\left(-194.5 y^{2}-7.22 y+2.76\right)\right] V^{2}+ \\
& {\left[(12.5 y-13.2) M H F+\left(33.1 y^{2}+34.42 y+0.59\right)\right] V+[(-7.65 y+} \\
& \left.5.74) M H F+\left(4.15 y^{2}-5.22 y+24.15\right)\right] \\
& T_{4 \mid\left(W F T=0.5 \times 10^{-3} \mathrm{~m}\right)}=\left[(8.14 y-6.74) M H F+\left(-51.4 y^{2}+55.39 y-\right.\right. \\
& 9.94)] V^{3}+\left[(-23.89 y+18.06) M H F+\left(157.77 y^{2}-135.11 y+21.62\right)\right] V^{2}+ \\
& {\left[(24.81 y-17.19) M H F+\left(-122.41 y^{2}+92.91 y-13.17\right)\right] V+} \\
& {\left[\left((-10.63 y+6.63) M H F+\left(26 y^{2}-17.68 Y+27.61\right)\right)\right]} \\
& T_{5 \mid\left(W F T=0.5 \times 10^{-3} \mathrm{~m}\right)}=\left[(8.87 y-7.77) M H F+\left(17.86 y^{2}+22.17 y-4.75\right)\right] V^{3}+ \\
& {\left[(-25.72 y+20.22) M H F+\left(38.15 y^{2}-80.69 y+13.5\right)\right] V^{2}+[(26.51 y-} \\
& \left.18.72) M H F+\left(-64 y^{2}+69.43 y-9.96\right)\right] V+[(-11.27 y+6.96) M H F+ \\
& \left.\left(19.35 y^{2}-15.915 y+27.28\right)\right]
\end{aligned}
$$

where WFT is the water film thickness. Furthermore, the following equations are derived to obtain the values for $T_{2}, T_{3}, T_{4}$, and $T_{5}$ temperature variations with $V, M H F$ and $y$-coordinate at $0.7 \times 10^{-3} \mathrm{~m}$ and $0.8 \times 10^{-3} \mathrm{~m}$ water film thicknesses:

$$
\begin{aligned}
& T_{2 \mid\left(W F T=0.7 \times 10^{-3} \mathrm{~m}\right)}=\left[(-2.49 y-2.55) M H F+\left(875.98 y^{2}-462.48 y+\right.\right. \\
& 59.31)] V^{3}+\left[(-0.76 y+7.77) M H F+\left(-1647.2 y^{2}+899.31 y-\right.\right. \\
& 123.37)] V^{2}+\left[(6.75 y-7.87) M H F+\left(989.38 y^{2}-563.32 y+83.94\right)\right] V+ \\
& {\left[(-4.51 y+4.23) M H F+\left(-193.6 y^{2}+118.2 y+6.68\right)\right]}
\end{aligned}
$$




$$
\begin{aligned}
& T_{2 \mid\left(W F T=0.8 \times 10^{-3} \mathrm{~m}\right)}=\left[(0.59 y-3.31) M H F+\left(854.22 y^{2}-429.52 y+\right.\right. \\
& 48.08)] V^{3}+\left[(-7.68 y+9.48) M H F+\left(-1766.7 y^{2}+937.84 y-\right.\right. \\
& 116.68)] V^{2}+\left[(11.55 y-8.97) M H F+\left(1166 y^{2}-651.83 y+89.07\right)\right] V+ \\
& {\left[(-5.39 y+4.34) M H F+\left(-246.4 y^{2}+146.68 y+4.236\right)\right]} \\
& T_{3 \mid\left(W F T=0.7 \times 10^{-3} \mathrm{~m}\right)}=\left[(0.0045 y-4.66) M H F+\left(911.51 y^{2}-466.93 y+\right.\right. \\
& 55.37)] V^{3}+\left[(-8.82 y+13.78) M H F+\left(-1709 y^{2}+909.18 y-\right.\right. \\
& 117.26)] V^{2}+\left[(15.49 y-13.84) M H F+\left(1030.2 y^{2}-574.27 y+\right.\right. \\
& \text { 82.08) }] V+\left[(-8.23 y+5.75) M H F+\left(-203.4 y^{2}+122.14 y+6.98\right)\right] \\
& T_{3 \mid\left(W F T=0.8 \times 10^{-3} \mathrm{~m}\right)}=\left[(3.85 y-5.52) M H F+\left(1101.1 y^{2}-560.13 y+\right.\right. \\
& 59.77)] V^{3}+\left[(-17.49 y+15.73) M H F+\left(-2301.3 y^{2}+1231.4 y-\right.\right. \\
& 146.58)] V^{2}+\left[(21.47 y-15.05) M H F+\left(1536.2 y^{2}-860.87 y+\right.\right. \\
& 112.8)] V+\left[(-9.24 y+5.8) M H F+\left(-327.4 y^{2}+193.47 y-1.069\right)\right] \\
& T_{4 \mid\left(W F T=0.7 \times 10^{-3} \mathrm{~m}\right)}=\left[(9.34 y-7.08) M H F+\left(366.36 y^{2}-200.35 y+\right.\right. \\
& 24.71)] V^{3}+\left[(-27.14 y+18.98) M H F+\left(-733.56 y^{2}+414.93 y-\right.\right. \\
& 54.32)] V^{2}+\left[(27.55 y-17.88) M H F+\left(473.82 y^{2}-277.16 y+38.59\right)\right] V+ \\
& {\left[(-11.14 y+6.62) M H F+\left(-99.75 y^{2}+60.7 y+16.56\right)\right]} \\
& T_{4 \mid\left(W F T=0.8 \times 10^{-3} \mathrm{~m}\right)}=\left[(11.39 y-7.47) M H F+\left(564.92 y^{2}-307.73 y+\right.\right. \\
& 34.8)] V^{3}+\left[(-31.79 y+19.79) M H F+\left(-1214.4 y^{2}+681.72 y-\right.\right. \\
& 82.12)] V^{2}+\left[(30.68 y-18.23) M H F+\left(830.41 y^{2}-478.1 y+60.8\right)\right] V+ \\
& {\left[(-11.47 y+6.44) M H F+\left(-180.25 y^{2}+106.42 y+11.36\right)\right]} \\
& T_{5 \mid\left(W F T=0.7 \times 10^{-3} \mathrm{~m}\right)}=\left[(10.76 y-8.38) M H F+\left(332.38 y^{2}-174.51 y+\right.\right. \\
& 22.8)] V^{\wedge} 3+\left[(-30.13 y+21.61) M H F+\left(-634.75 y^{2}+343.3 y-\right.\right. \\
& 47.05)] V^{\wedge} 2+\left[(29.86 y-19.65) M H F+\left(385.13 y^{2}-215.33 y+31.29\right)\right] V+ \\
& {\left[(-11.88 y+6.986) M H F+\left(-76.1 y^{2}+44.85 y+18.41\right)\right]} \\
& T_{5 \mid\left(W F T=0.8 \times 10^{-3} \mathrm{~m}\right)}=\left[(13.04 y-8.87) M H F+\left(389.86 y^{2}-201.62 y+\right.\right. \\
& 23.58)] V^{3}+\left[(-35.09 y+22.57) M H F+\left(-820.35 y^{2}+441.75 y-\right.\right.
\end{aligned}
$$




$$
\begin{aligned}
& 55.17)] V^{2}+\left[(33.09 y-20.04) M H F+\left(549.7 y^{2}-306.92 y+40.68\right)\right] V+ \\
& {\left[(-12.19 y+6.797) M H F+\left(-117.2 y^{2}+68.18 y+15.85\right)\right]}
\end{aligned}
$$

The contour plots of $T_{1}, T_{5}$ and $\left(t_{5}-t_{1}\right)$ for water film thickness equals $0.5 \times 10^{3} \mathrm{~m}$, as presented in Fig. 9, give detailed visual descriptions of these empirical equations. The variation of dependent variables $T_{1}, T_{5}$ and $\left(t_{5}-t_{1}\right)$ with $V, M H F, x$ and $y$ coordinates parameters are illustrated in Fig. 9. The accuracy of the derived empirical equations is verified by comparing their predictions with those obtained from our SPH model. MATLAB is used to generate heat maps of temperature as shown in Fig. 10 and Fig. 11 for the glass using our empirical equations and SPH model, respectively, with three different combinations of the down-flowing velocity of water film $(V)$, maximum heat flux $(M H F)$ and water film thickness (WFT). Temperature variation with time is also compared between our SPH model and the empirical equations at P3, P13 and P18 points for different three combinations of our analysis parameters as shown in Figs. 12 to 15 . Both results are well aligned indicating the adequacy of the derived empirical equations.

\section{Case studies and applications}

\subsection{Optimization of the water film system}

Both the down-flowing velocity and thickness of water film determine the volume flow rate of water used in glass cooling. Our empirical equations are utilized to compare the efficiency between increasing down-flowing velocity and thickness of water film at a specific volume flow rate. Two cases were studied, the first case involves an increase in water film thickness from $0.5 \times 10^{-3} \mathrm{~m}$ to $0.8 \times 10^{-3} \mathrm{~m}$ while the second case involves an increment of the down-flowing velocity of water film from $0.3 \mathrm{~m} / \mathrm{s}$ to $1 \mathrm{~m} / \mathrm{s}$. We observed that the water volume flow rate increased by $60 \%$ in the first case and $233 \%$ in the second case. The value of temperature $T_{5}$ was also calculated as $M H F$ varies from 
$9 \mathrm{~kW} \cdot \mathrm{m}^{-2}$ to $21 \mathrm{~kW} \cdot \mathrm{m}^{-2}$ using Eqs. (17), (24) and (25) at different $y$-coordinate values as detailed in Table 2. The percentage of water volume flow rate increment for each 1 ${ }^{\circ} \mathrm{C}$ decrement in glass temperature $\left(T_{5}\right)$ is lower in the second case (which involves increased down-flowing velocity) for all values of $M H F$ and $y$-coordinate. Accordingly, it is concluded that increasing the down-flowing velocity of water film is more efficient in glass cooling than increasing water film thickness.

\subsection{Evaporation}

The variation of the maximum temperature of water film with maximum heat flux $(M H F)$, water film velocity $(V)$ and $y$-coordinate is investigated in this section. It is clear that water film temperature increases with time during fire until it reaches a maximum value almost at the same time that the maximum heat flux reaches its maximum value. The main objective of this section is to determine water evaporation conditions and how it can be minimized in order to increase the overall efficiency of the water film system. Mathematical derivations were carried-out at the second layer of the water film adjacent to glass $\left(x=-0.1 \times 10^{-3} \mathrm{~m}, y=0 \mathrm{~m}\right)$ as shown in Fig. 16. Water film temperature values at different cases of water velocity $(V), M H F$ and $y$-coordinate are obtained using our SPH model. The maximum water film temperature $(M T W)$ decreases when down-flowing velocity increases and heat flux decreases, also the water film temperature increases as it flows down from the top of the glass $(y=0.6 \mathrm{~m})$ to the bottom $(y=0.00 \mathrm{~m})$. The following equations were used to calculate the maximum water film temperature $(M T W)$ at water film thicknesses of $0.5 \times 10^{-3} \mathrm{~m}, 0.7 \times 10^{-3} \mathrm{~m}$ and $0.8 \times 10^{-3} \mathrm{~m}:$

$$
\begin{aligned}
& M T W_{\mid\left(W F T=0.5 \times 10^{-3} \mathrm{~m}\right)}=(-14.15 M H F y+8.41 M H F) V^{2}+(25.75 M H F y+ \\
& -15.06 M H F) V+(-13.74 M H F y+7.79 M H F+24.86)
\end{aligned}
$$


$M T W_{\mid\left(W F T=0.7 \times 10^{-3} \mathrm{~m}\right)}=(-16.19 M H F y+8.94 M H F) V^{2}+(27.74 M H F y-$

15.19MHF)V + (-13.61MHFy + 7.32MHF+24.86)

$M T W_{\mid\left(W F T=0.8 \times 10^{-3} \mathrm{~m}\right)}=(-15.55 M H F y+8.1 M H F) V^{2}+(25.85 M H F y-$

13.41MHF $) V+(-11.89 M H F y+6.12 M H F+24.85)$

The minimum velocity of water film required to prevent evaporation was calculated when $y$-coordinate equals zero (at the bottom of the glass) and $M T W$ equals $100{ }^{\circ} \mathrm{C}$ (water evaporation temperature) as shown below:

$V_{\min \mid\left(W F T=0.5 \times 10^{-3} \mathrm{~m}\right)}=\frac{15.06-\sqrt{-35.22+\frac{2567.71}{M H F}}}{16.82}$

$V_{\min \mid\left(W F T=0.7 \times 10^{-3} \mathrm{~m}\right)}=\frac{15.19-\sqrt{-30.96+\frac{2688.5}{M H F}}}{17.89}$

$V_{\min \mid\left(W F T=0.8 \times 10^{-3} \mathrm{~m}\right)}=\frac{13.41-\sqrt{-18.27+\frac{2434.05}{M H F}}}{16.12}$

where $V_{\min }$ is the minimum down-flowing velocity of water film to prevent evaporation in $\mathrm{m} / \mathrm{s}$. The variation of $V_{\min }$ with maximum heat flux $(M H F)$ at different water film thicknesses $\left(W F T=0.5 \times 10^{-3} \mathrm{~m}, W F T=0.7 \times 10^{-3} \mathrm{~m}\right.$ and $\left.W F T=0.8 \times 10^{-3} \mathrm{~m}\right)$ is shown in Fig. 17, it is clear that the velocity of water film has to be increased to prevent evaporation when $M H F$ increases and vice versa. However, when water film thickness increases, the required minimum velocity $\left(V_{m i n}\right)$ decreases. 


\section{Conclusion}

In this paper, the SPH method is employed to simulate the cooling process of glass by water film based on the discretization of the heat energy equation. The computational framework of the temperature distribution during fire in both glass and water film was established based on the validated SPH model. Empirical equations were derived to relate temperature variations with heat flux, down-flowing velocity and thickness of water film. Before applying the water film, the temperature across the glass section decreases linearly at any given time. It was observed that when water film is applied, the temperature of glass particles near water film drops sharply with time. However, glass particles located farther away from the water film require more time to cool down.

The newly derived empirical equations were employed to examine the optimum configuration for the water film glass protection system and to prevent evaporation of the down-flowing water film, thus enhancing its overall efficiency. In order to ensure that a lower amount of water is used to protect the glass, it is recommended that the down-flowing velocity of water film should be increased rather than its thickness. The water film temperature plays a key role in our study because it directly affects the temperature distribution of glass. To prevent the evaporation of water film, the downflowing velocity of water film shall be kept above the minimum values stated in our work. 


\section{Declaration of Competing Interest}

The authors declare that they have no known competing financial interests or personal relationships that could have appeared to influence the work reported in this paper.

\section{CRediT authorship contribution statement}

D.A. Abdoh: Methodology, Formal analysis, Writing - original draft. A.S. Ademiloye: Conceptualization, Writing - review \& editing. K.M. Liew: Conceptualization, Methodology, Resources, Project administration, Supervision, Writing - review \& editing.

\section{Acknowledgments}

The authors gratefully acknowledge the supports provided by the Research Grants Council of the Hong Kong Special Administrative Region, China (Project No. 9042476, CityU 11201817). The first author, D.A. Abdoh, acknowledges the UGC-Postgraduate Studentship awarded by the Hong Kong Government to support his PhD program in the Department of Architecture and Civil Engineering, City University of Hong Kong, Hong Kong, China. 


\section{References}

[1] Grant G, Brenton J, Drysdale D. Fire suppression by water sprays. Prog Energy Combust Sci 2000;26:79-130. https://doi.org/10.1016/S0360-1285(99)00012-X.

[2] Hu WC, Nurcholik SD, Lee SK, Lin TH. Evaluations on heat resistance of curtains with water film in a fire. J Chinese Inst Eng Trans Chinese Inst Eng A 2016;39:615-22. https://doi.org/10.1080/02533839.2016.1146092.

[3] Kuznetsov G V, Osipov KY, Piskunov M V, Volkov RS. Experimental research of radiative heat transfer in a water film. Int $\mathrm{J}$ Heat Mass Transf 2018;117:1075-82. https://doi.org/10.1016/j.ijheatmasstransfer.2017.10.082.

[4] Brissinger D, Parent G, Boulet P. Experimental study on radiation attenuation by a water film. J Quant Spectrosc Radiat Transf 2014;145:160-8. https://doi.org/10.1016/j.jqsrt.2014.04.020.

[5] Hu WC, Nurcholik SD, Lee SK, Lin TH. Evaluations on heat resistance of curtains with water film in a fire. J Chinese Inst Eng Trans Chinese Inst Eng A 2016;39:615-22. https://doi.org/10.1080/02533839.2016.1146092.

[6] Wu CW, Lin TH. Full-scale evaluations on heat resistance of glass panes incorporated with water film or sprinkler in a room fire. Build Environ 2007;42:3277-84. https://doi.org/10.1016/j.buildenv.2006.08.017.

[7] Wang Q, Shao G, Wang Y, Zhao H, Sun J, He L. Thermal breakage and fallout behaviors of non-tempered glass under the effect of water film. J Fire Sci 2015;33:390-404. https://doi.org/10.1177/0734904115599668.

[8] Shao G, Wang Q, Zhao H, Wang Y, Chen H, Su Y, et al. Maximum temperature to withstand water film for tempered glass exposed to fire. Constr Build Mater 2014;57:1523. https://doi.org/10.1016/j.conbuildmat.2014.01.094.

[9] Wu CW, Lin TH, Lei MY, Chung TH, Huang CC, Chiang WT. Fire resistance tests of a glass pane with down-flowing water film. J Chinese Inst Eng 2008;31:737-44. https://doi.org/10.1080/02533839.2008.9671428.

[10] Sharshir SW, Peng G, Wu L, Yang N, Essa FA, Elsheikh AH, et al. Enhancing the solar still performance using nanofluids and glass cover cooling: Experimental study. Appl Therm Eng 2017;113:684-693. https://doi.org/10.1016/j.applthermaleng.2016.11.085.

[11] Monnoyer F, Lochegnies D. Heat transfer and flow characteristics of the cooling system of an industrial glass tempering unit. Appl Therm Eng 2008;28:2167-2177. https://doi.org/10.1016/j.applthermaleng.2007.12.014.

[12] Chen HT, Lee SK. Estimation of heat-transfer characteristics on the hot surface of glass pane with down-flowing water film. Build Environ 2010;45:2089-99. https://doi.org/10.1016/j.buildenv.2010.03.005. 
[13] Ren C, Wan Y. A new approach to the analysis of heat and mass transfer characteristics for laminar air flow inside vertical plate channels with falling water film evaporation. Int J Heat Mass Transf 2016;103:1017-1028. https://doi.org/10.1016/j.ijheatmasstransfer.2016.07.109.

[14] Wan Y, Ren C, Yang Y, Xing L. Study on average Nusselt and Sherwood numbers in vertical plate channels with falling water film evaporation. Int J Heat Mass Transf 2017;110:783-788. https://doi.org/10.1016/j.ijheatmasstransfer.2017.03.087.

[15] Grysa K, Maciag A, Cebo-Rudnicka A, Walaszczyk M. Identification of the heat transfer coefficient during cooling process by means of Trefftz method. Eng Anal Bound Elem 2018;95:33-9. https://doi.org/10.1016/j.enganabound.2018.07.001.

[16] Zhang LW, Ademiloye AS, Liew KM. Meshfree and Particle Methods in Biomechanics: Prospects and Challenges 2019;26:1547-1576. https://doi.org/10.1007/s11831-0189283-2.

[17] Abdoh DA, Kodur VKR, Liew KM. Smoothed particle hydrodynamics modeling of the thermal behavior of double skin facades in fires considering the effects of venetian blinds. Appl Math Model 2020;84:357-76. https://doi.org/10.1016/j.apm.2020.02.033.

[18] Chen HT, Lee SK. Estimation of heat-transfer characteristics on the hot surface of glass pane with down-flowing water film. Build Environ 2010;45:2089-99. https://doi.org/10.1016/j.buildenv.2010.03.005.

[19] Gingold RA, Monaghan JJ. Smoothed particle hydrodynamics: theory and application to non-spherical stars. Mon Not R Astron Soc 1977;181:375-389. https://doi.org/10.1093/mnras/181.3.375.

[20] Liu GR, Liu MB. Smoothed Particle Hydrodynamics - A Meshfree Particle Method. 2010. https://doi.org/10.1142/9789812564405.

[21] Wang L, Xu F, Yang Y, Wang J. A dynamic particle refinement strategy in Smoothed Particle Hydrodynamics for Fluid-Structure Interaction problems. Eng Anal Bound Elem 2019;100:140-9. https://doi.org/10.1016/j.enganabound.2018.01.012.

[22] Vignjevic R, Campbell J, Jaric J, Powell S. Derivation of SPH equations in a moving referential coordinate system. Comput Methods Appl Mech Eng 2009;198:2403-11. https://doi.org/10.1016/j.cma.2009.02.027.

[23] Ngo-Cong D, Tran CD, Mai-Duy N, Tran-Cong T. Incompressible smoothed particle hydrodynamics-moving IRBFN method for viscous flow problems. Eng Anal Bound Elem 2015;59:172-86. https://doi.org/10.1016/j.enganabound.2015.06.006.

[24] Liu MB, Zhang Z. Smoothed particle hydrodynamics (SPH) for modeling fluid-structure interactions. Sci China Physics, Mech Astron 2019;62. https://doi.org/10.1007/s11433$\underline{018-9357-0 .}$

[25] Yang X, Kong SC. Numerical study of natural convection in a horizontal concentric annulus using smoothed particle hydrodynamics. Eng Anal Bound Elem 2019;102:1120. https://doi.org/10.1016/j.enganabound.2019.02.007. 
[26] Rook R, Yildiz M, Dost S. Modeling transient heat transfer using SPH and implicit time integration. Numer Heat Transf Part B Fundam 2007;51:1-23. https://doi.org/10.1080/10407790600762763.

[27] Jeong JH, Jhon MS, Halow JS, Van Osdol J. Smoothed particle hydrodynamics: Applications to heat conduction. Comput Phys Commun 2003;153:71-84. https://doi.org/10.1016/S0010-4655(03)00155-3.

[28] $\mathrm{Ng} \mathrm{KC}, \mathrm{Ng}$ YL, Sheu TWH, Alexiadis A. Assessment of Smoothed Particle Hydrodynamics (SPH) models for predicting wall heat transfer rate at complex boundary. Eng Anal Bound Elem 2020;111:195-205. https://doi.org/10.1016/j.enganabound.2019.10.017.

[29] Abdoh DA, Ademiloye AS, Liew KM. Modeling glass cooling mechanism with downflowing water film via the smoothed particle hydrodynamics. Comput Methods Appl Mech Eng 2020;362:112839. https://doi.org/10.1016/j.cma.2020.112839. 


\section{Down-flowing water film}

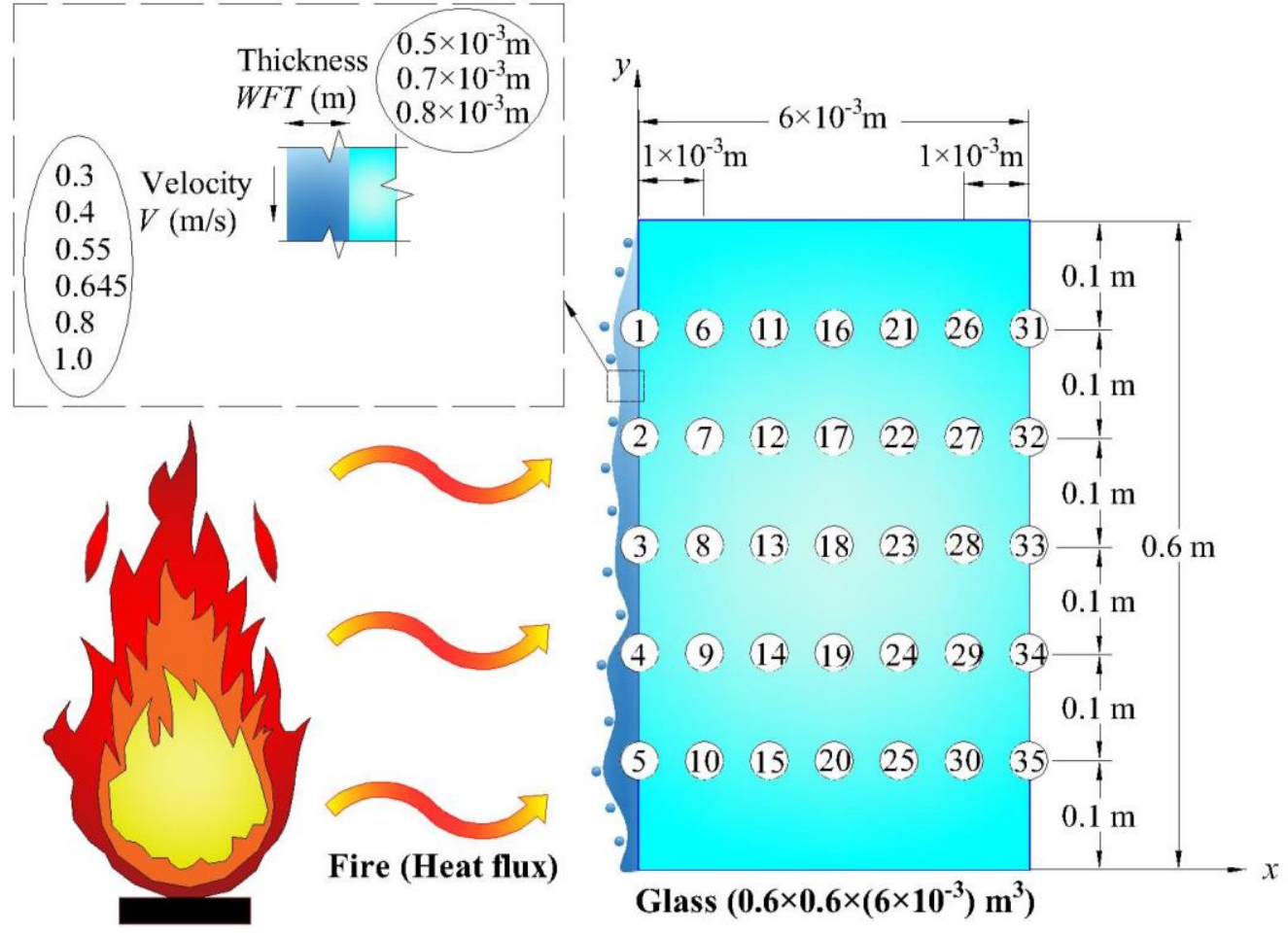

(a)

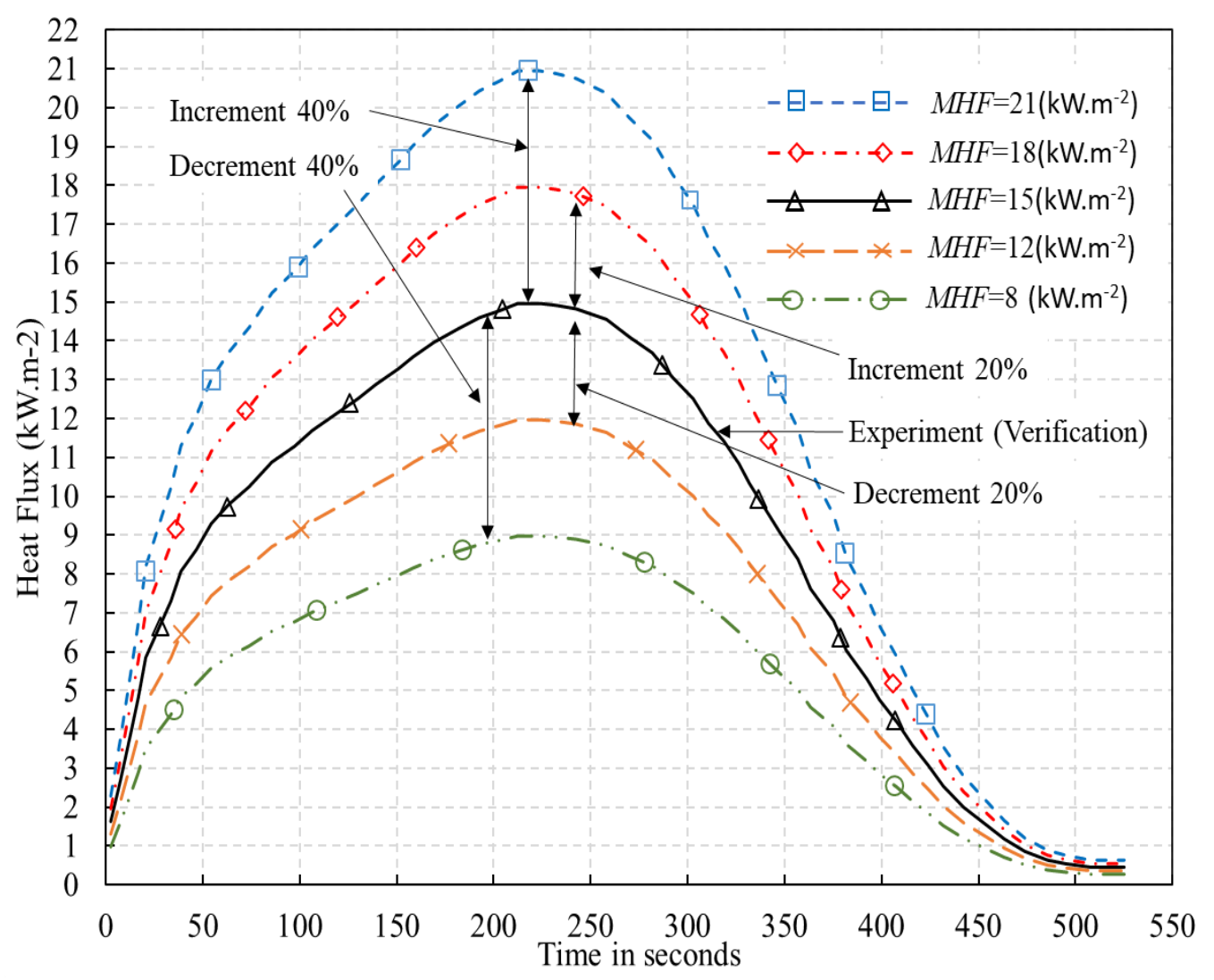

(b)

Fig. 1. Problem description diagrams: (a) Geometry description and parameters; (b) Heat flux variations with time. 


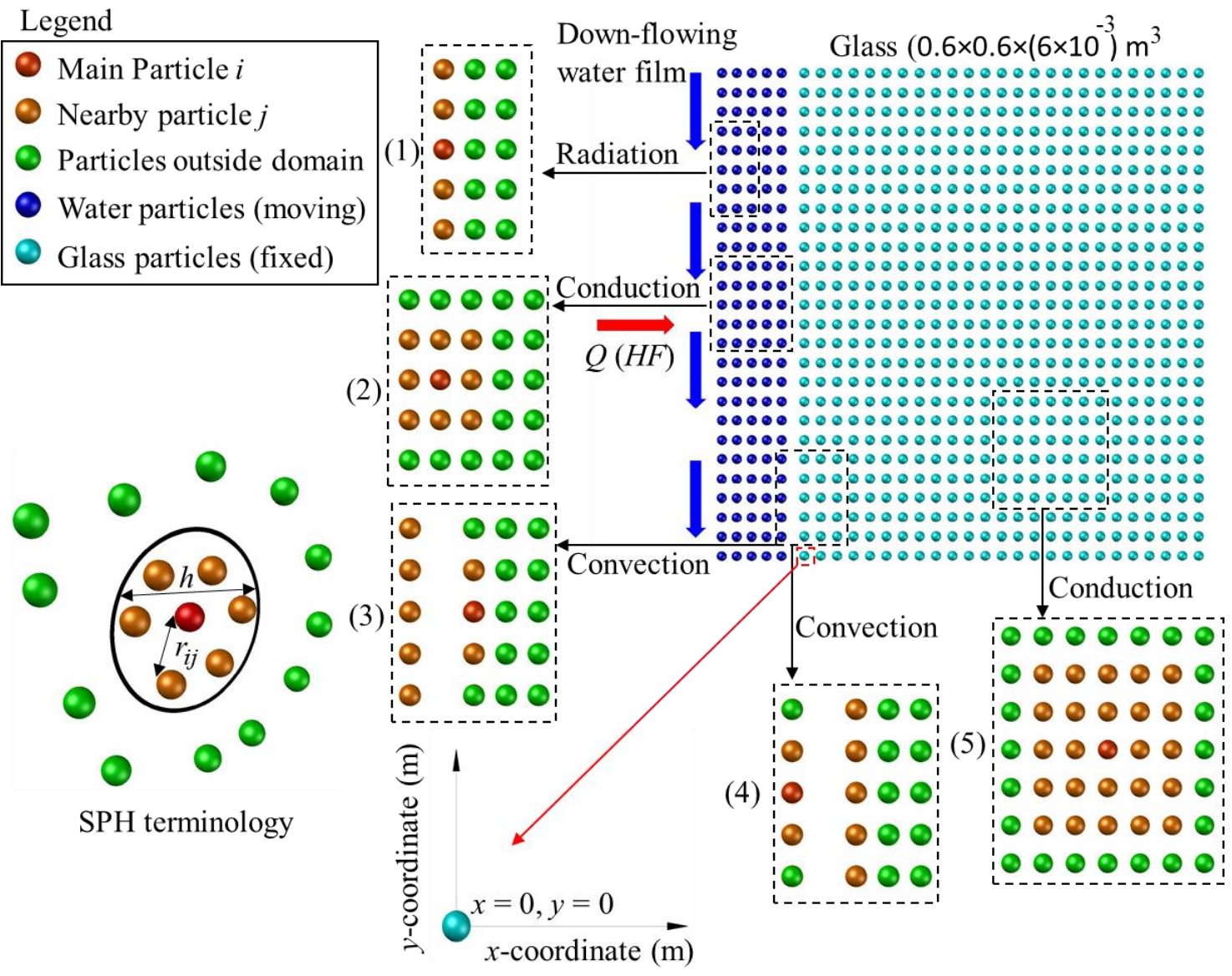

Fig. 2. SPH methodology description of glass cooling by down-flowing water film.

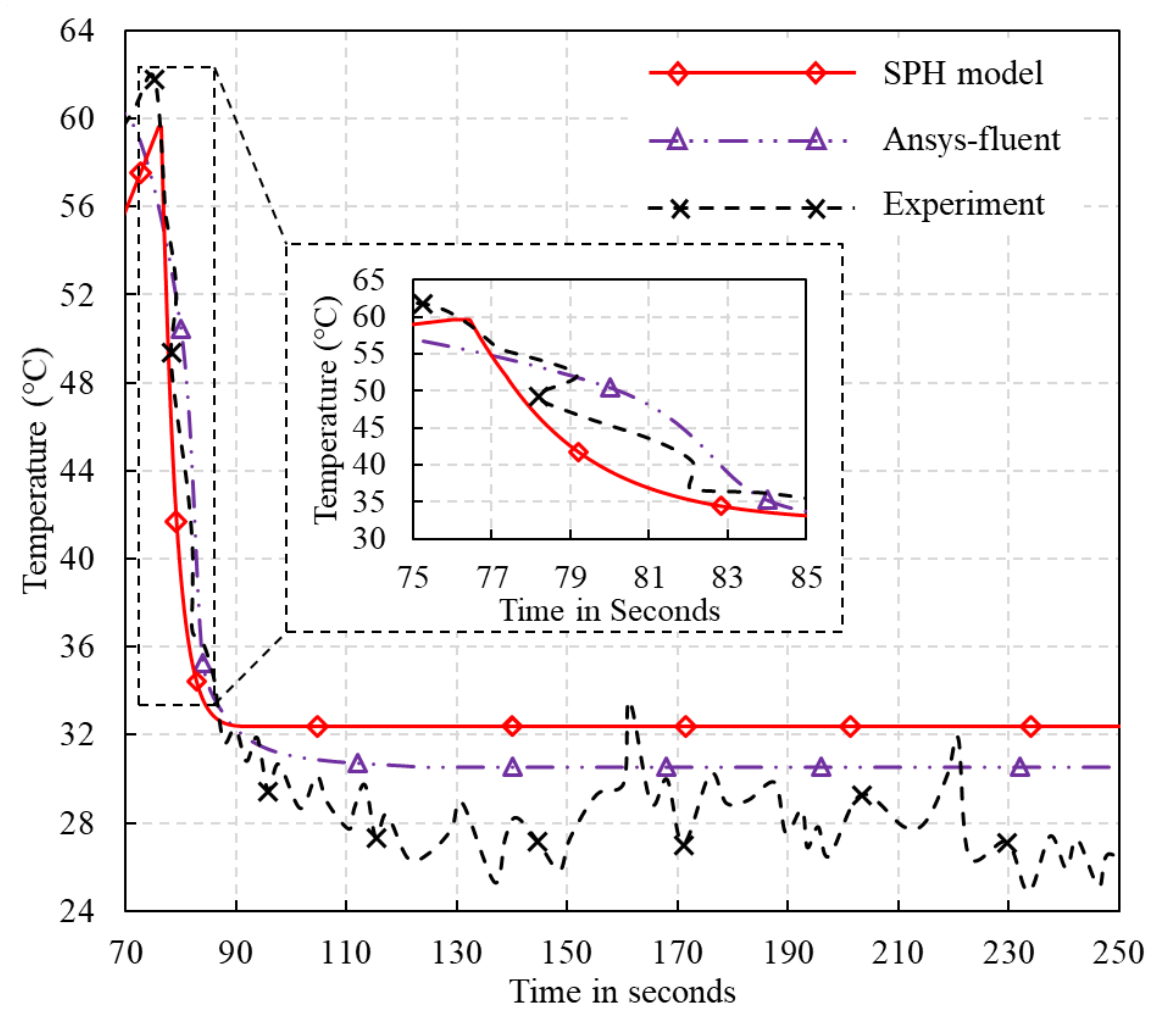

Fig. 3. Temperature variation with time using SPH model, Ansys-Fluent and experiment at point P3 (exposed surface) 


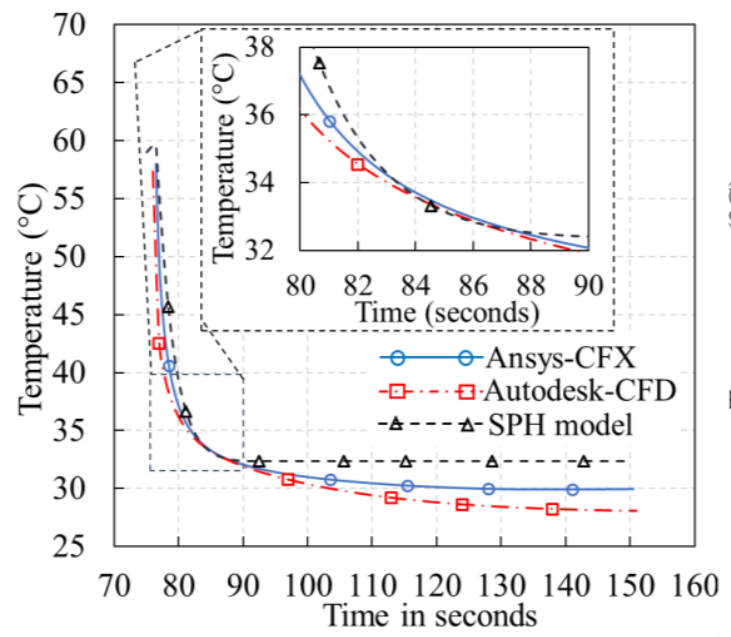

(a)

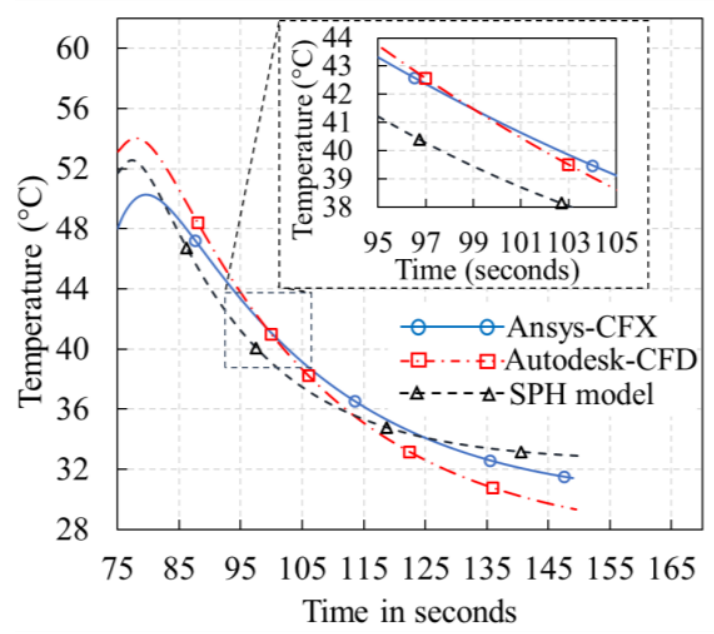

(c)

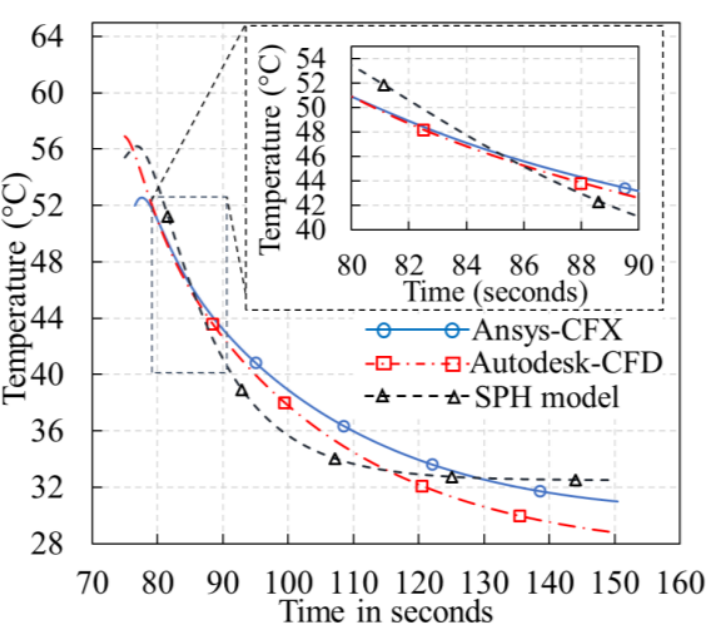

(b)

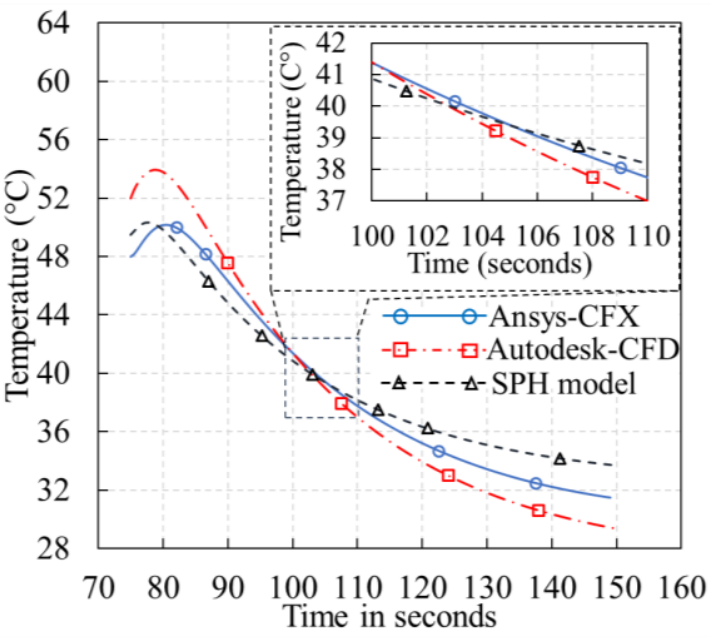

(d)

Fig. 4. Temperature variation with time after applying water film using our SPH model, Ansys-CFX and Autodesk-CFD: (a) At point P3; (b) At Point P18; (c) At Point P28; (d) At Point P33. 

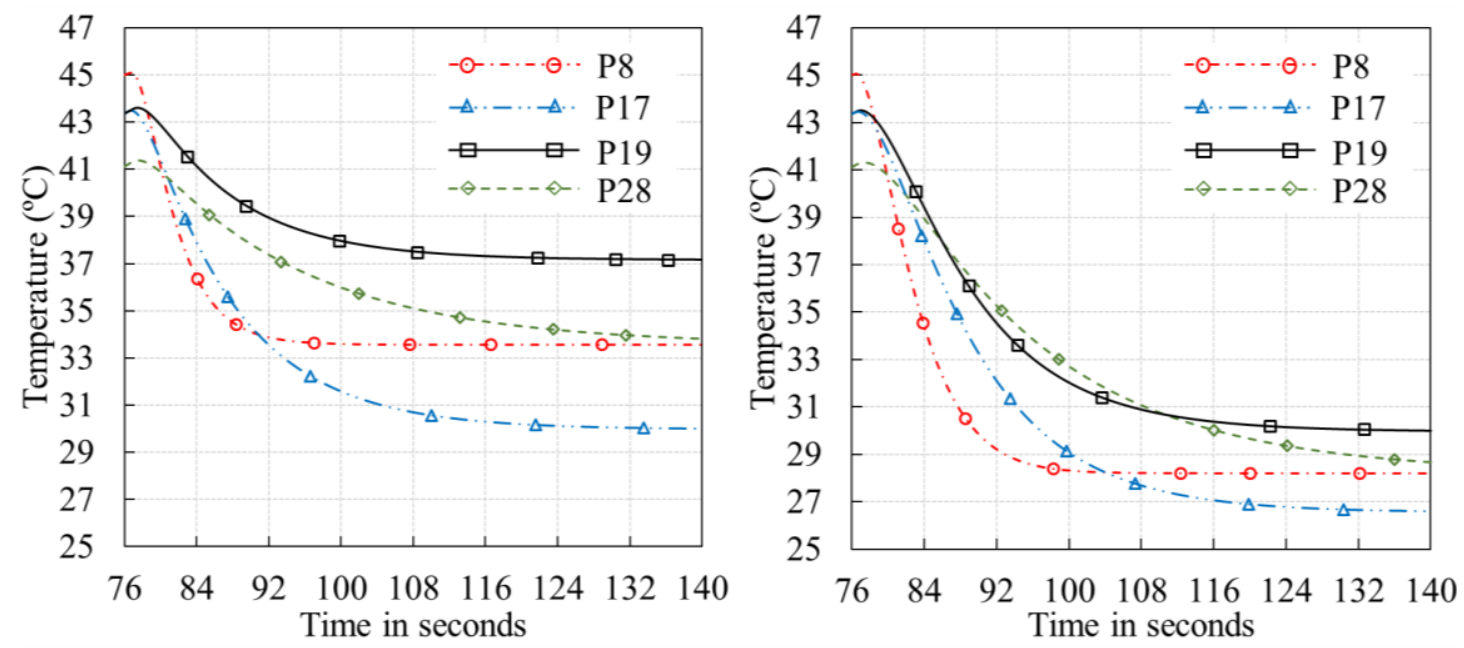

(a)

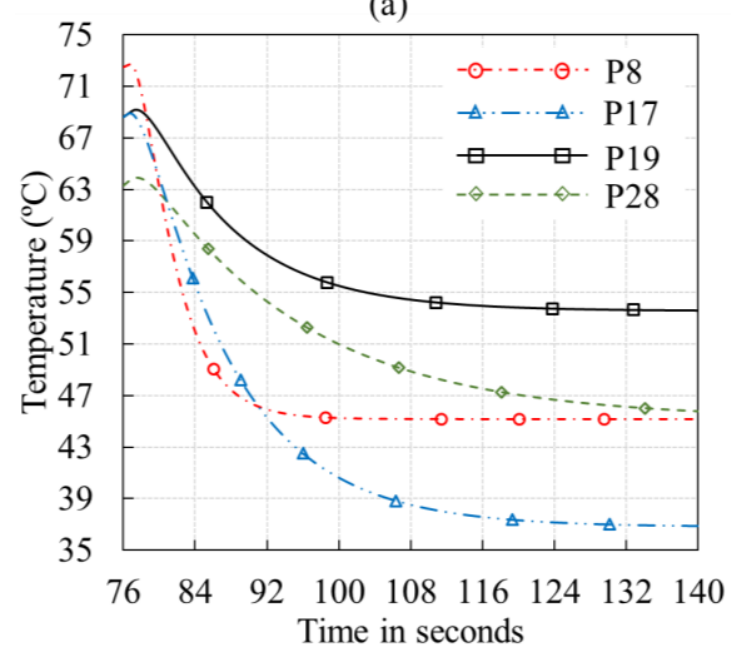

(c)

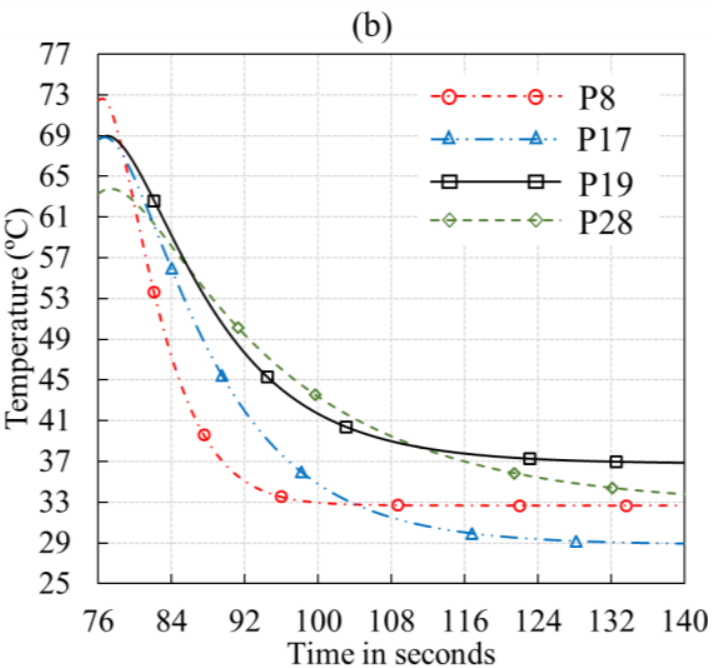

(d)

Fig. 5. Temperature variation with time after applying $0.5 \times 10^{-3} \mathrm{~m}$ water film thickness $\left(W F T=0.5 \times 10^{-3} \mathrm{~m}\right)$ using our SPH model at P8, P17, P19 and P28 points: (a) At $V=$ $0.4 \mathrm{~m} / \mathrm{s}$ and $M H F=9 \mathrm{~kW} \cdot \mathrm{m}^{-2}$; (b) At $V=0.8 \mathrm{~m} / \mathrm{s}$ and $M H F=9 \mathrm{~kW} \cdot \mathrm{m}^{-2}$; (c) At $V=0.4$ $\mathrm{m} / \mathrm{s}$ and $M H F=21 \mathrm{~kW} \cdot \mathrm{m}^{-2} ;(\mathrm{d})$ At $V=0.8 \mathrm{~m} / \mathrm{s}$ and $M H F=21 \mathrm{~kW} \cdot \mathrm{m}^{-2}$. 

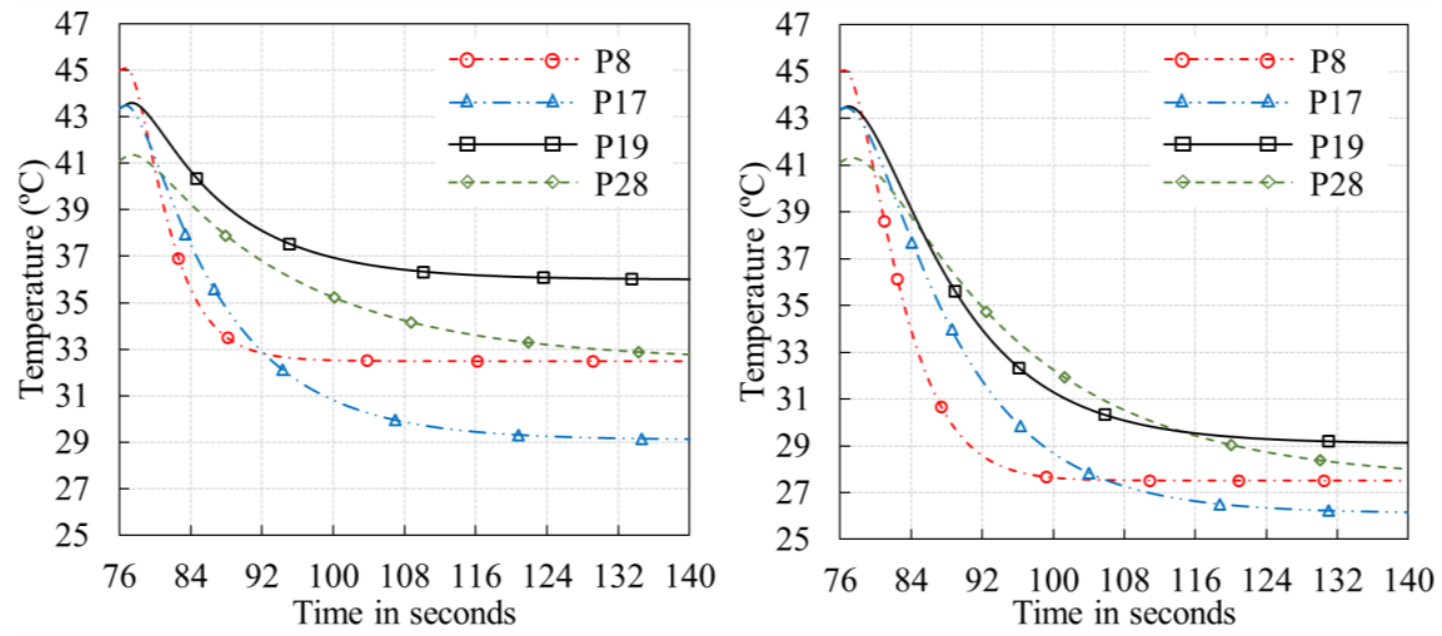

(a)

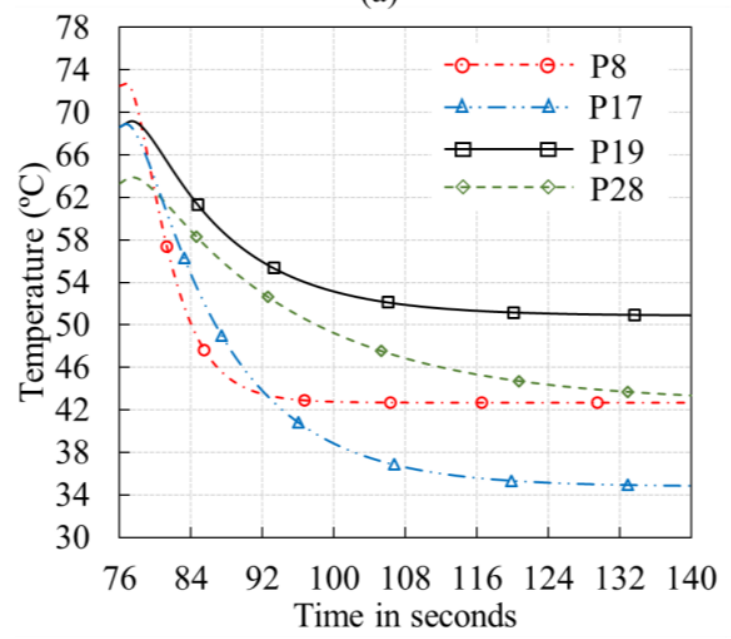

(c)

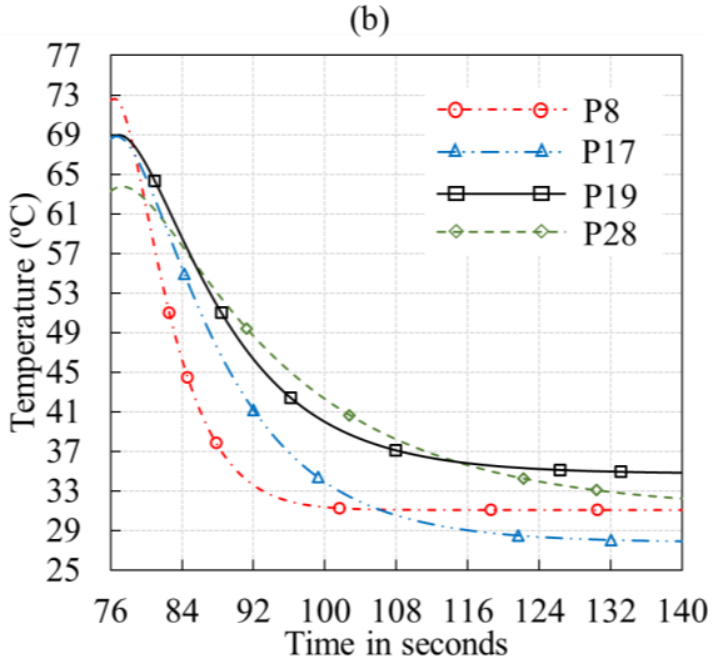

(d)

Fig. 6. Temperature variation with time after applying $0.7 \times 10^{-3} \mathrm{~m}$ water film thickness $\left(W F T=0.7 \times 10^{-3} \mathrm{~m}\right)$ using our SPH model at P8, P17, P19 and P28 points: (a) At $V=$ $0.4 \mathrm{~m} / \mathrm{s}$ and $M H F=9 \mathrm{~kW} \cdot \mathrm{m}^{-2}$; (b) At $V=0.8 \mathrm{~m} / \mathrm{s}$ and $M H F=9 \mathrm{~kW} \cdot \mathrm{m}^{-2}$; (c) At $V=0.4$ $\mathrm{m} / \mathrm{s}$ and $M H F=21 \mathrm{~kW} \cdot \mathrm{m}^{-2}$;(d) At $V=0.8 \mathrm{~m} / \mathrm{s}$ and $M H F=21 \mathrm{~kW} \cdot \mathrm{m}^{-2}$. 


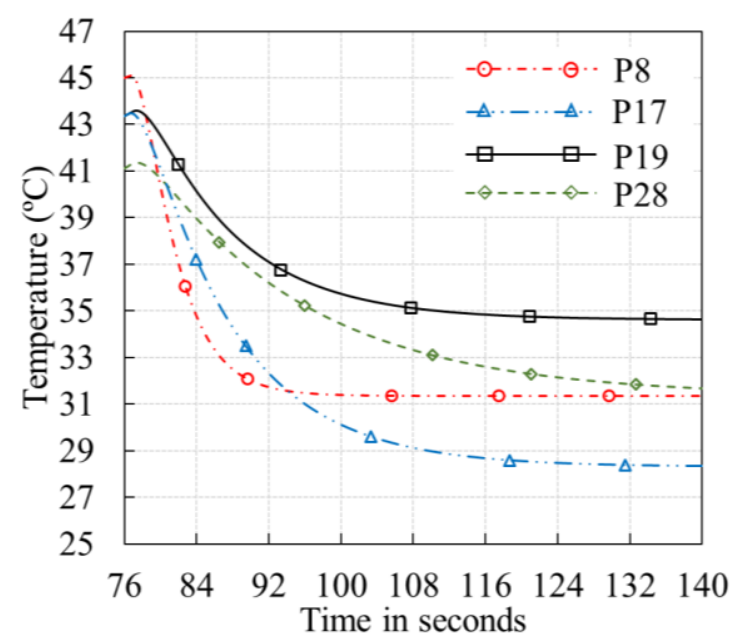

(a)

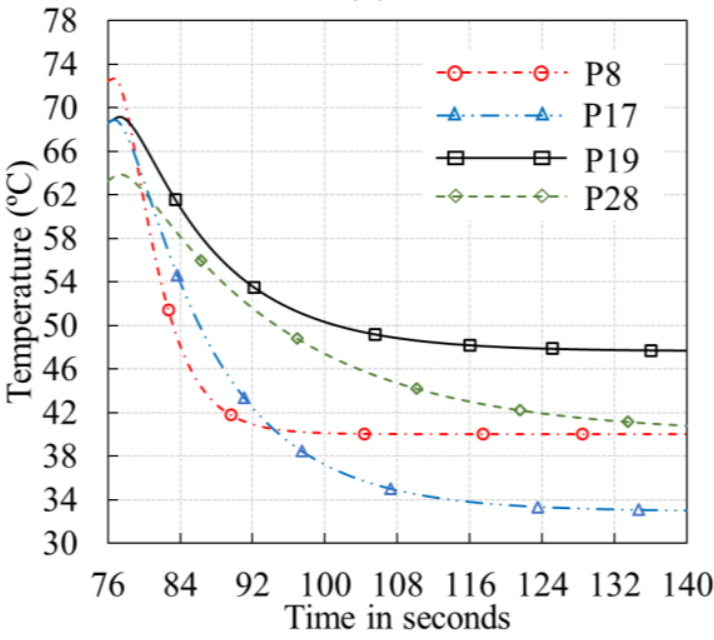

(c)

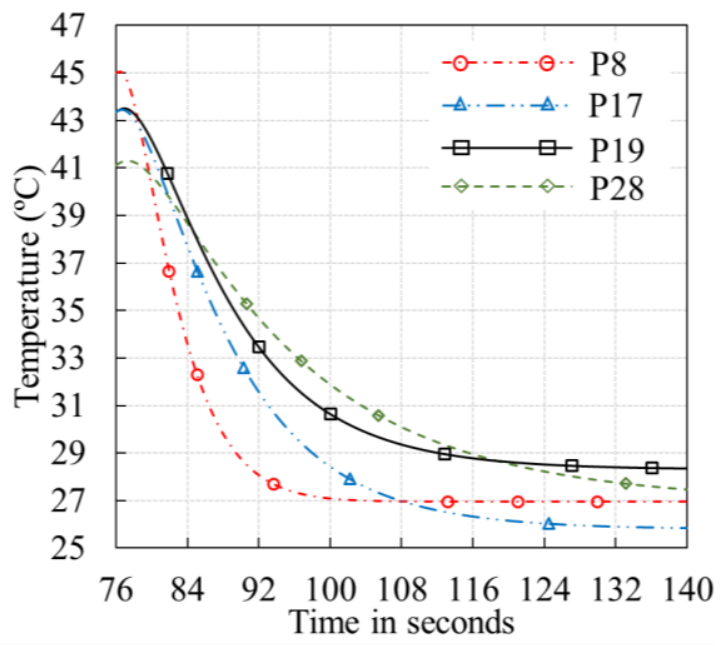

(b)

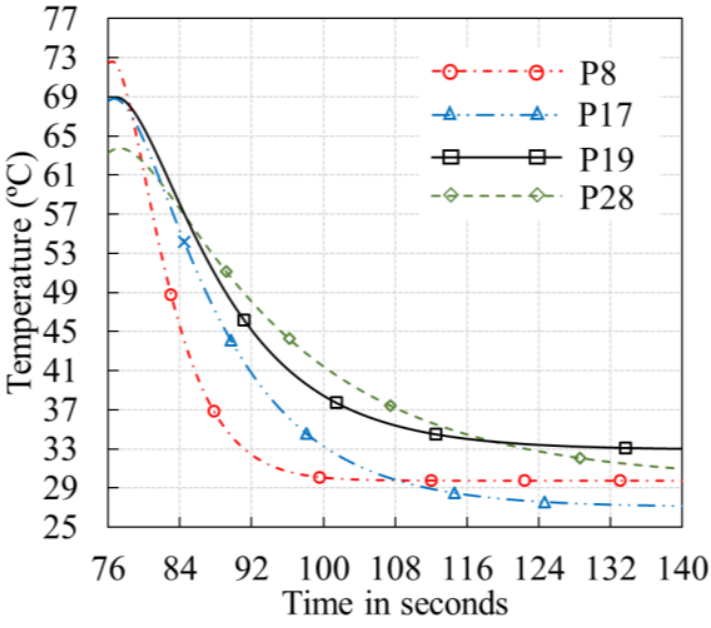

(d)

Fig. 7. Temperature variation with time after applying $0.8 \times 10^{-3} \mathrm{~m}$ water film thickness $\left(W F T=0.8 \times 10^{-3} \mathrm{~m}\right)$ using our SPH model at P8, P17, P19 and P28 points: (a) At $V=$ $0.4 \mathrm{~m} / \mathrm{s}$ and $M H F=9 \mathrm{~kW} \cdot \mathrm{m}^{-2}$; (b) At $V=0.8 \mathrm{~m} / \mathrm{s}$ and $M H F=9 \mathrm{~kW} \cdot \mathrm{m}^{-2}$; (c) At $V=0.4$ $\mathrm{m} / \mathrm{s}$ and $M H F=21 \mathrm{~kW} \cdot \mathrm{m}^{-2} ;(\mathrm{d})$ At $V=0.8 \mathrm{~m} / \mathrm{s}$ and $M H F=21 \mathrm{~kW} \cdot \mathrm{m}^{-2}$. 


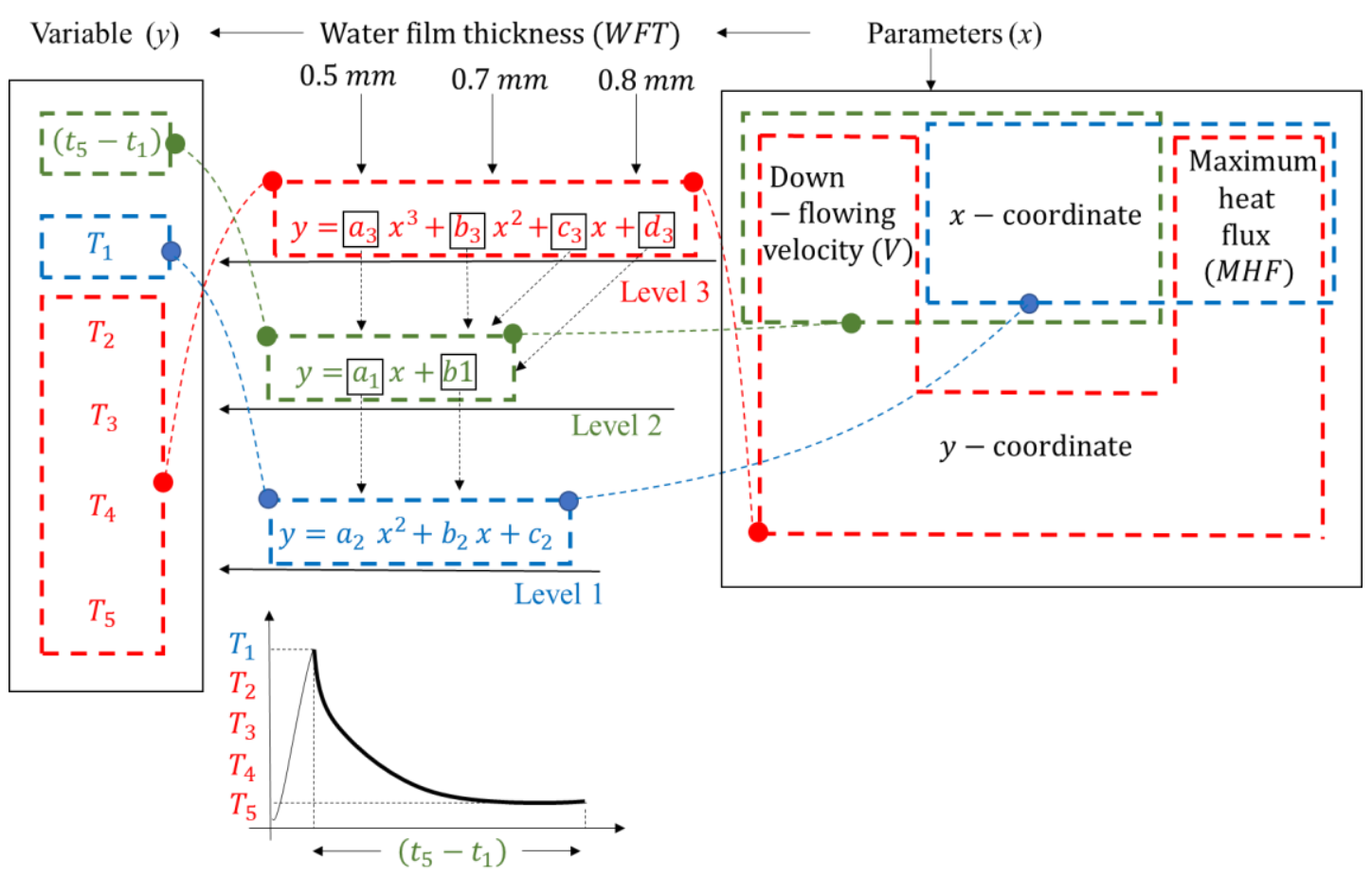

Fig. 8. Illustrative diagram for empirical equations derivations showing the relationship between different parameters and temperature values. 


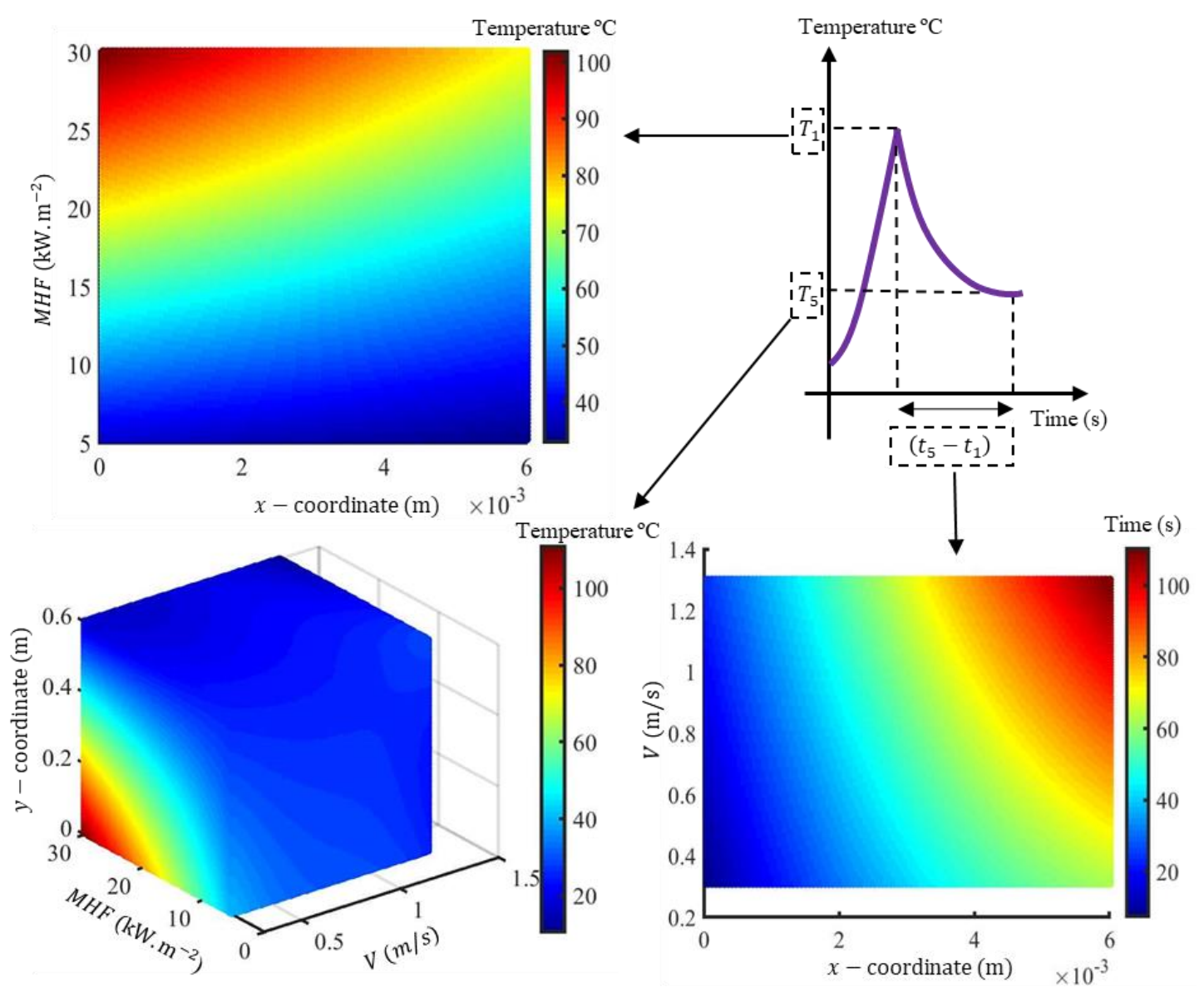

Fig. 9. Contour plot diagrams showing the relationship between $T_{1}, T_{5}$ and $\left(t_{5}-t_{1}\right)$ with various parameters $(M H F, V, x$-coordinate and $y$-coordinate) at water film thickness (WFT) equals $0.5 \times 10^{-3} \mathrm{~m}$. 

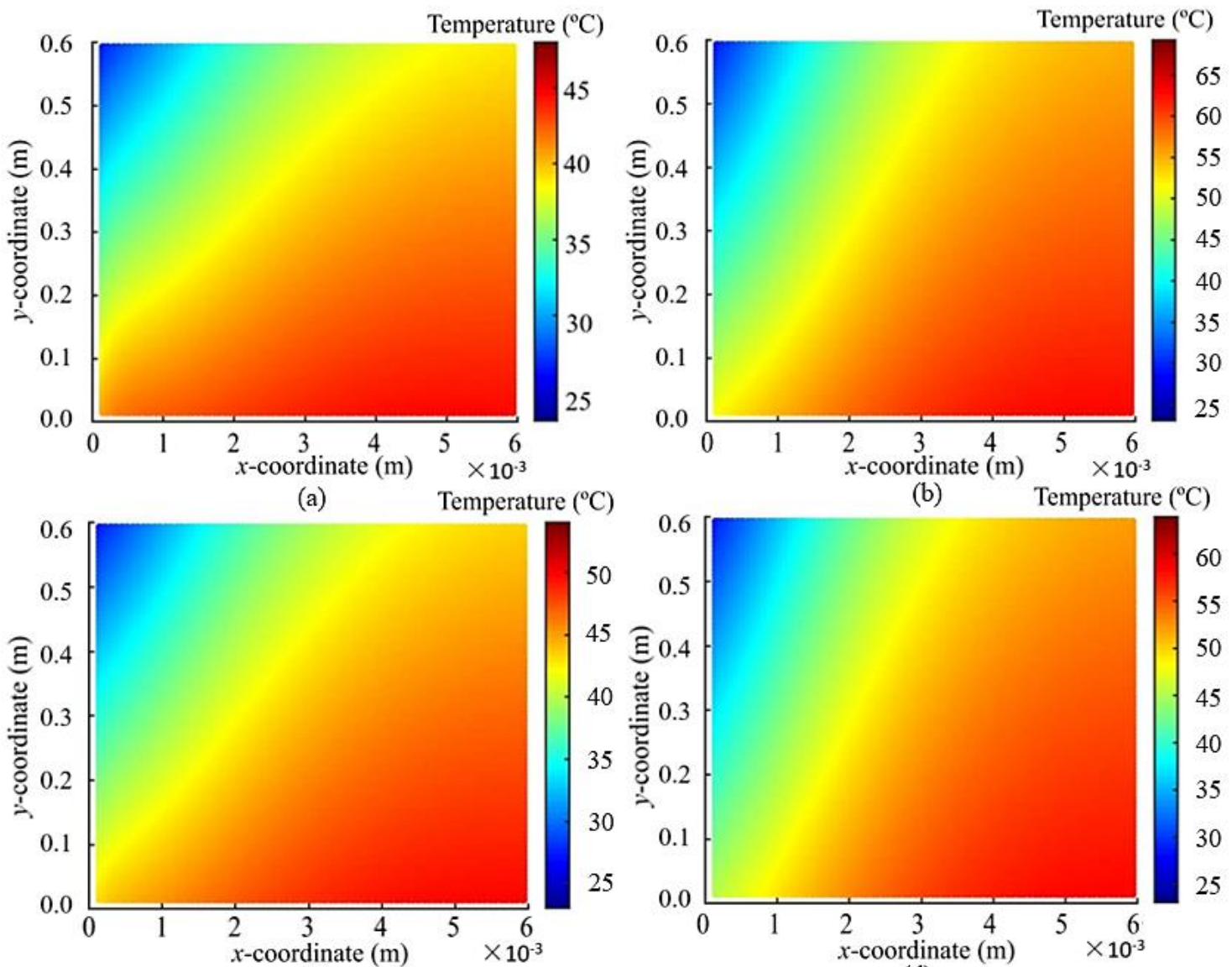

(c)

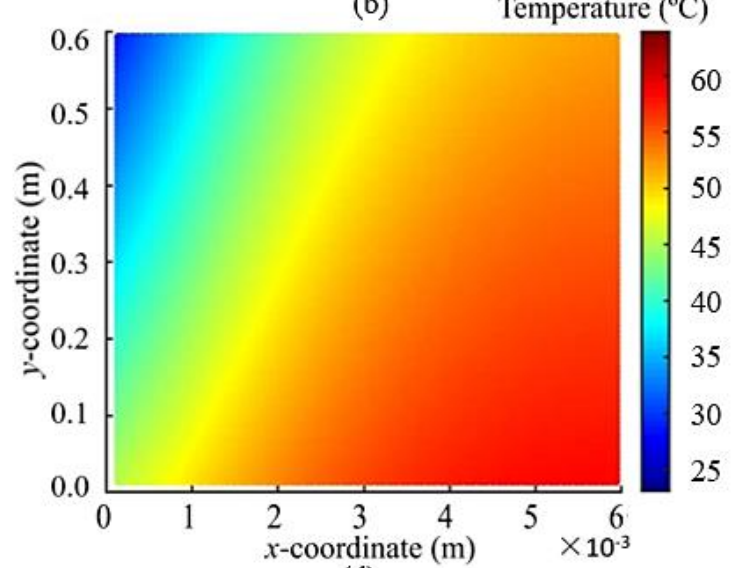

(d)

Fig. 10. Heat map of temperature $\left({ }^{\circ} \mathrm{C}\right)$ in glass at $t=9$ seconds from water flow using empirical equations: (a) At $V=0.55 \mathrm{~m} / \mathrm{s}, M H F=12 \mathrm{~kW} \cdot \mathrm{m}^{-2}$ and $W F T=0.5 \times 10^{-3} \mathrm{~m}$; (b) At $V=0.75 \mathrm{~m} / \mathrm{s}, M H F=25 \mathrm{~kW} \cdot \mathrm{m}^{-2}$ and $W F T=0.5 \times 10^{-3} \mathrm{~m}$; (c) At $V=0.6 \mathrm{~m} / \mathrm{s}, M H F$ $=16 \mathrm{~kW} \cdot \mathrm{m}^{-2}$ and $W F T=0.7 \times 10^{-3} \mathrm{~m}$; (d) At $V=0.7 \mathrm{~m} / \mathrm{s}, M H F=23 \mathrm{~kW} \cdot \mathrm{m}^{-2}$ and $W F T$ $=0.8 \times 10^{-3} \mathrm{~m}$. 


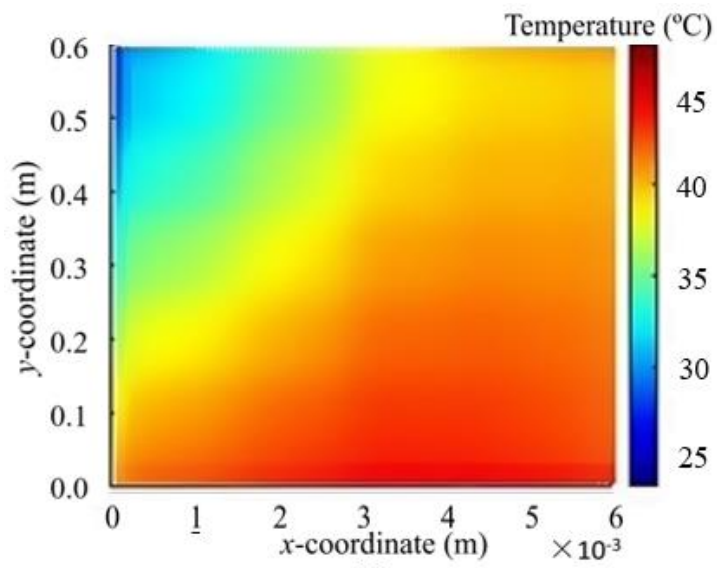

(a)
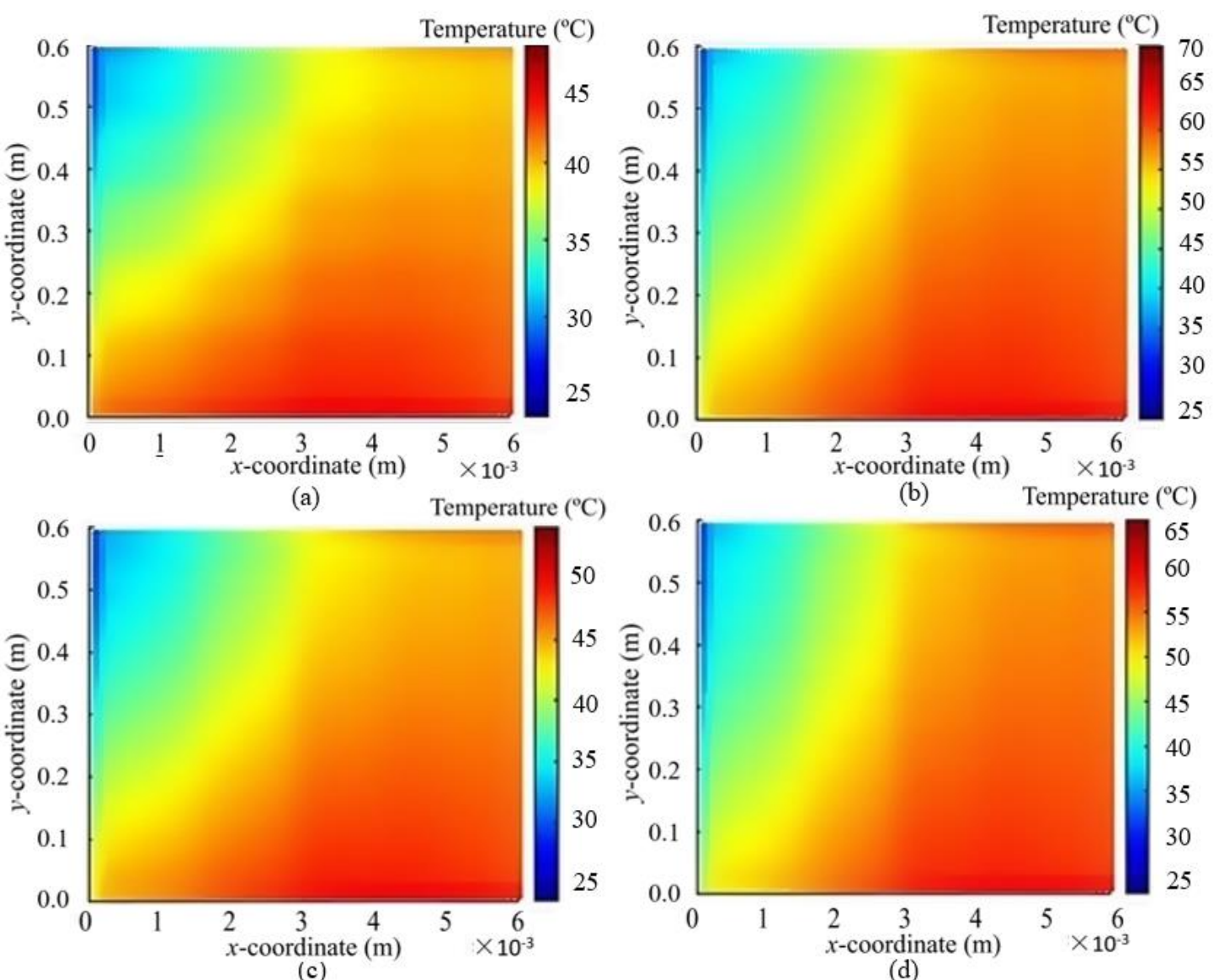

Fig. 11. Heat map of temperature $\left({ }^{\circ} \mathrm{C}\right)$ in glass at $t=9$ seconds from water flow using our SPH model: (a) At $V=0.55 \mathrm{~m} / \mathrm{s}, M H F=12 \mathrm{~kW} \cdot \mathrm{m}^{-2}$ and $W F T=0.5 \times 10^{-3} \mathrm{~m}$; (b) At $V=0.75 \mathrm{~m} / \mathrm{s}, M H F=25 \mathrm{~kW} \cdot \mathrm{m}^{-2}$ and $W F T=0.5 \times 10^{-3} \mathrm{~m}$; (c) At $V=0.6 \mathrm{~m} / \mathrm{s}, M H F=16$ $\mathrm{kW} \cdot \mathrm{m}^{-2}$ and $W F T=0.7 \times 10^{-3} \mathrm{~m}$; (d) At $V=0.7 \mathrm{~m} / \mathrm{s}, M H F=23 \mathrm{~kW} \cdot \mathrm{m}^{-2}$ and $W F T=$ $0.8 \times 10^{-3} \mathrm{~m}$. 


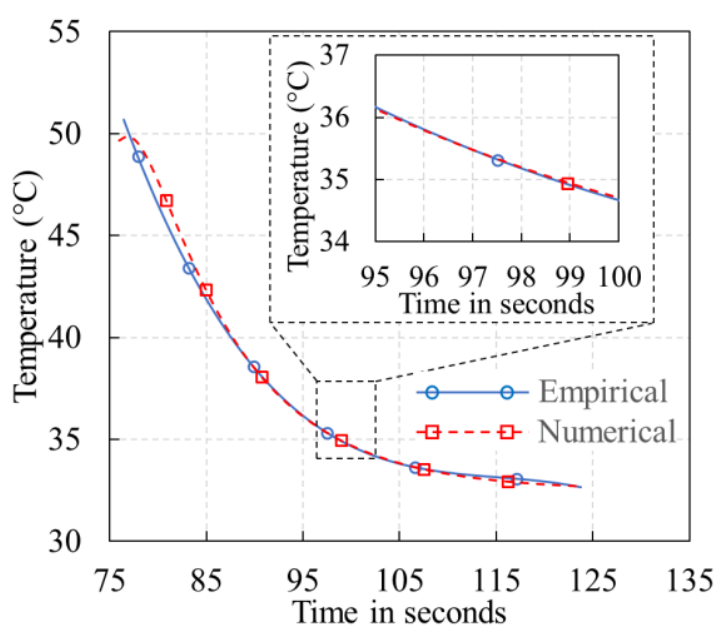

(a)

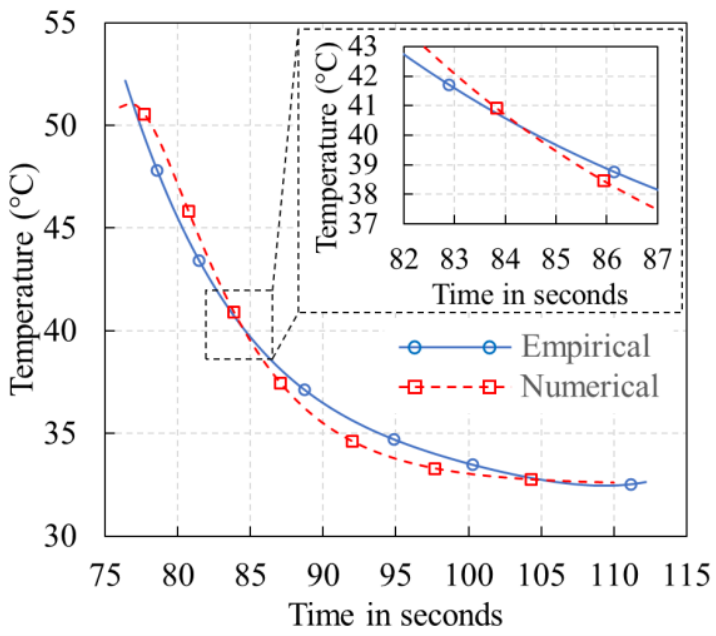

(c)

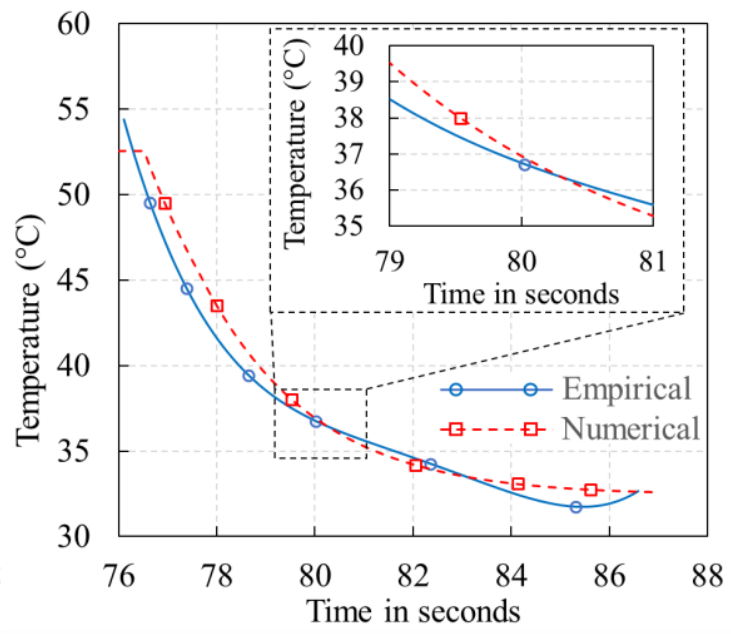

(b)

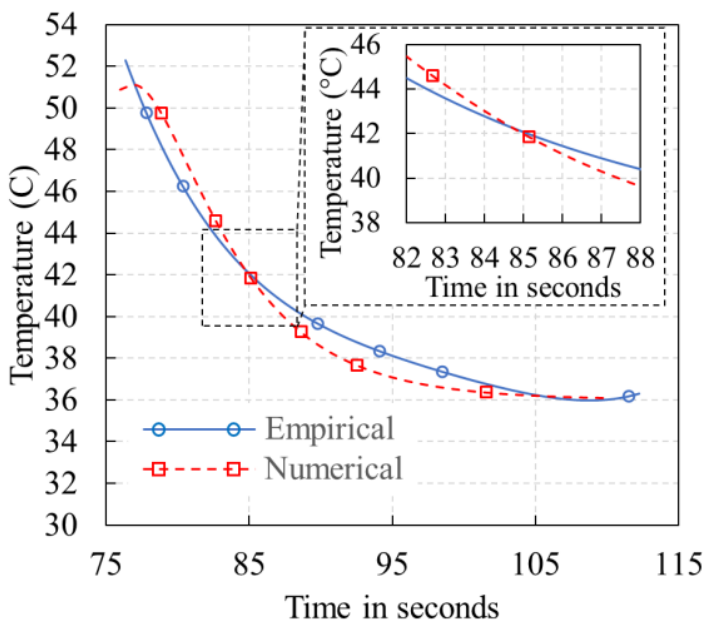

(d)

Fig. 12. Temperature variation with time obtained using our numerical model (SPH) and empirical equations at $V=0.55 \mathrm{~m} / \mathrm{s}, M H F=12 \mathrm{~kW} \cdot \mathrm{m}^{-2}$ and $W F T=0.5 \times 10^{-3} \mathrm{~m}$ : (a) P18; (b) P3; (c) P13; (d) P14. 


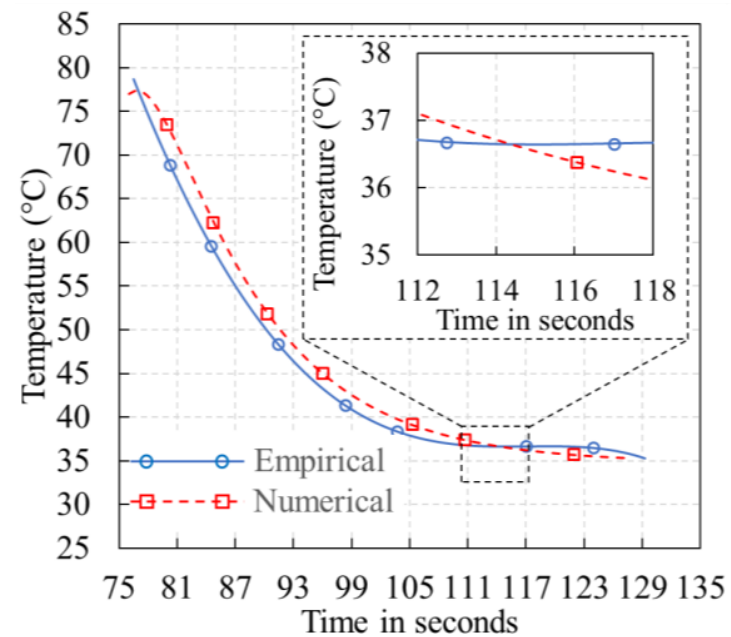

(a)

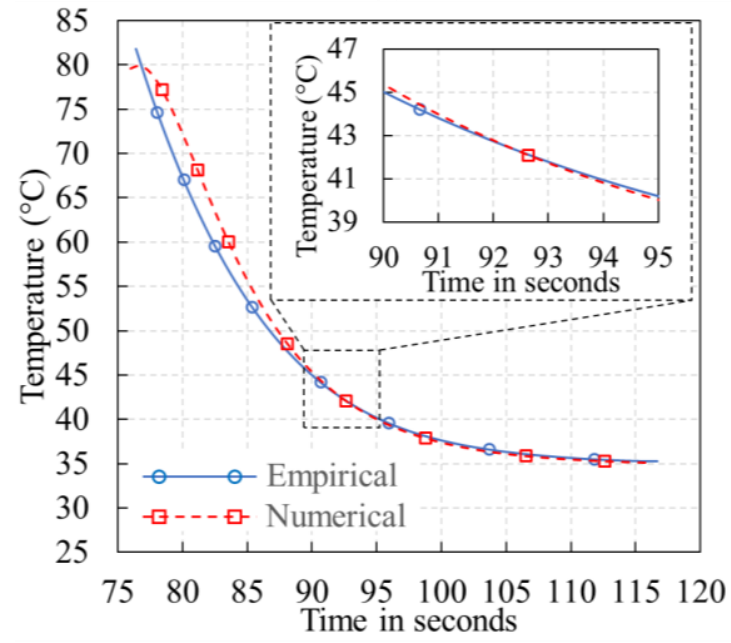

(c)

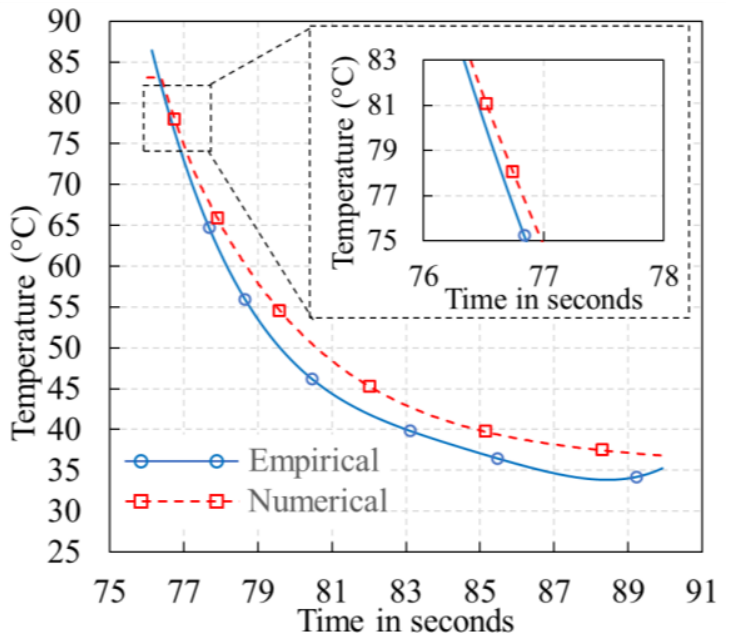

(b)

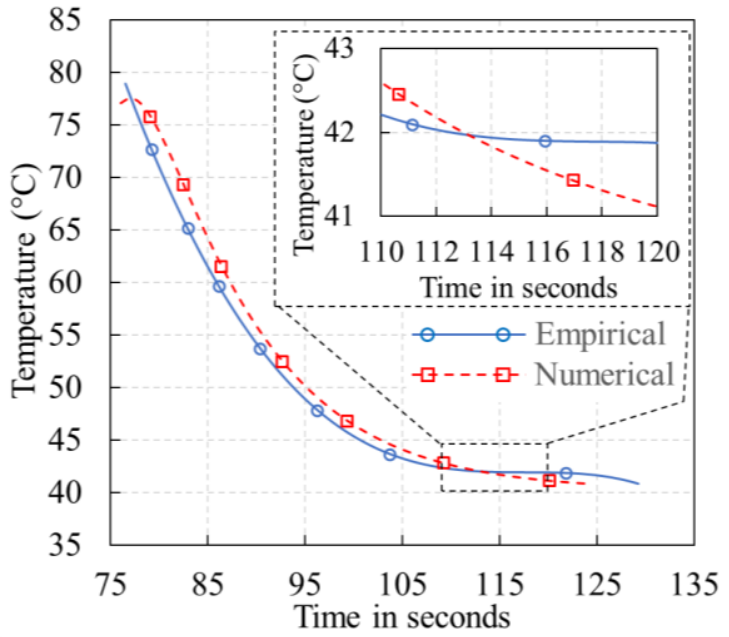

(d)

Fig. 13. Temperature variation with time obtained using our numerical model (SPH) and empirical equations at $V=0.75 \mathrm{~m} / \mathrm{s}, M H F=25 \mathrm{~kW} \cdot \mathrm{m}^{-2}$ and $W F T=0.5 \times 10^{-3} \mathrm{~m}$ : (a) P18; (b) P3; (c) P13; (d) P19. 


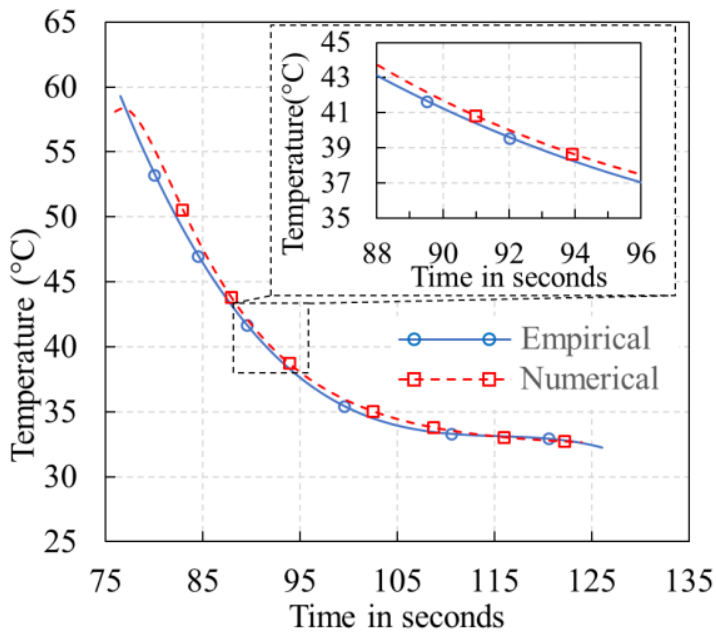

(a)

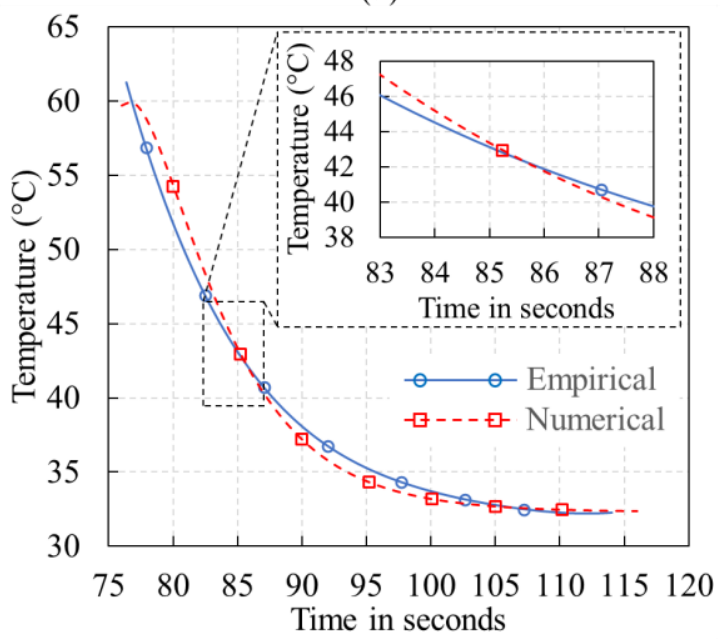

(c)

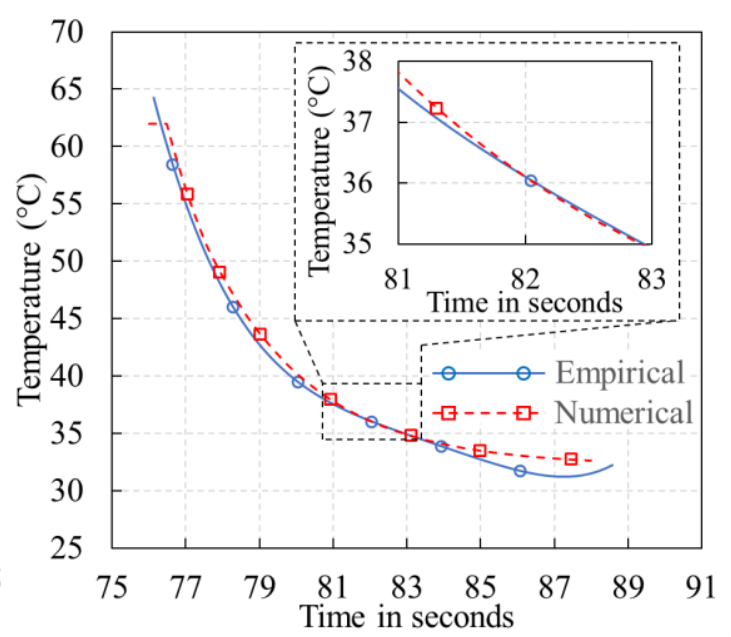

(b)

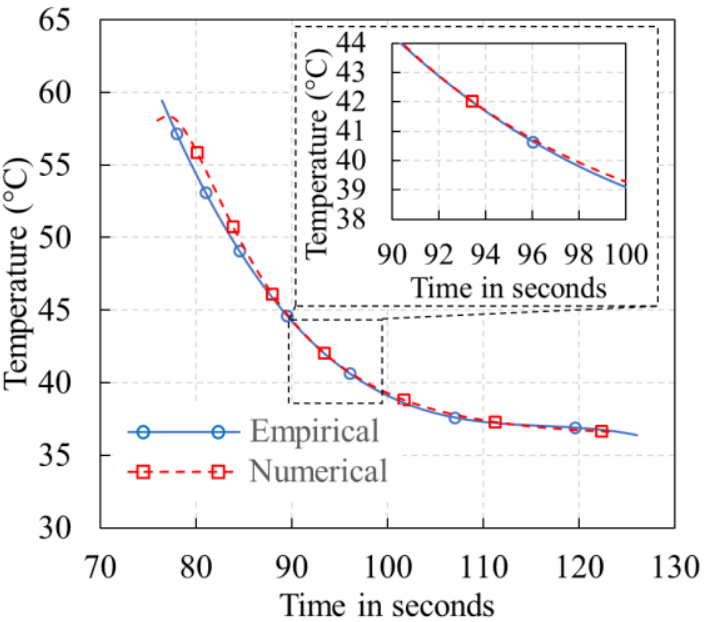

(d)

Fig. 14. Temperature variation with time obtained using our numerical model (SPH) and empirical equations at $V=0.60 \mathrm{~m} / \mathrm{s}, M H F=16 \mathrm{~kW} \cdot \mathrm{m}^{-2}$ and $W F T=0.7 \times 10^{-3} \mathrm{~m}$ : (a) P18; (b) P3; (c) P13; (d) P19. 


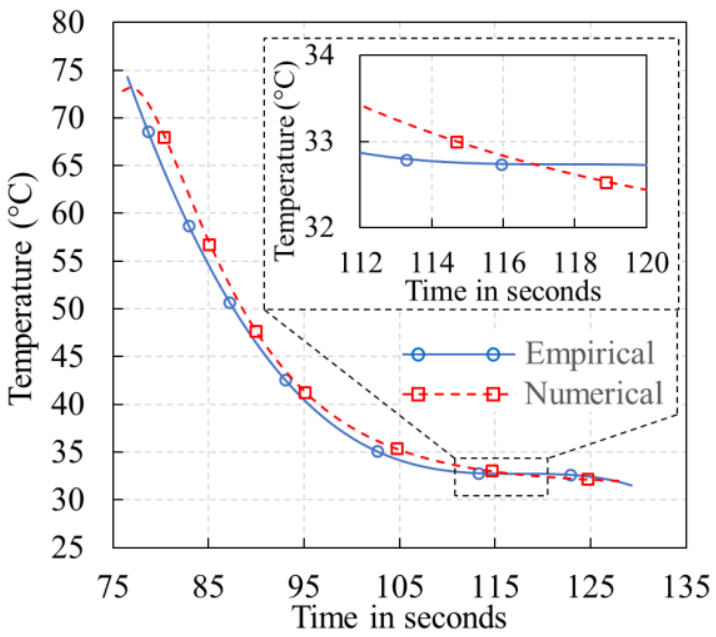

(a)

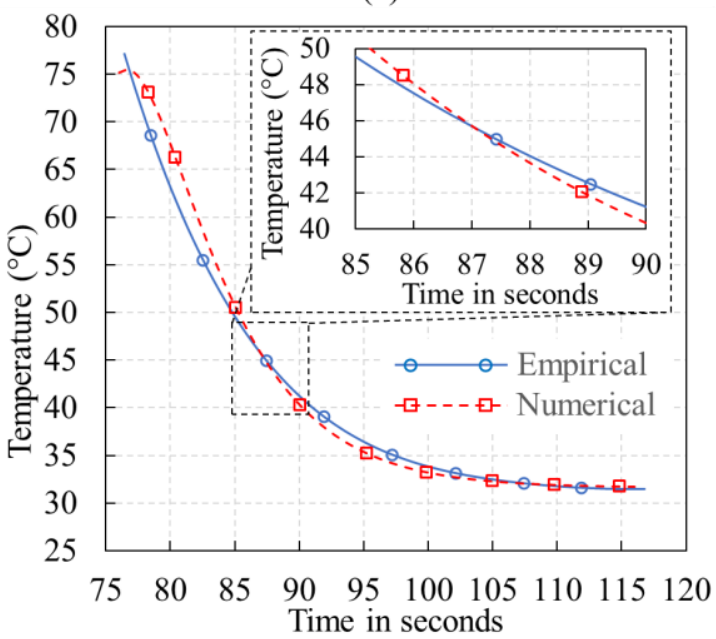

(c)

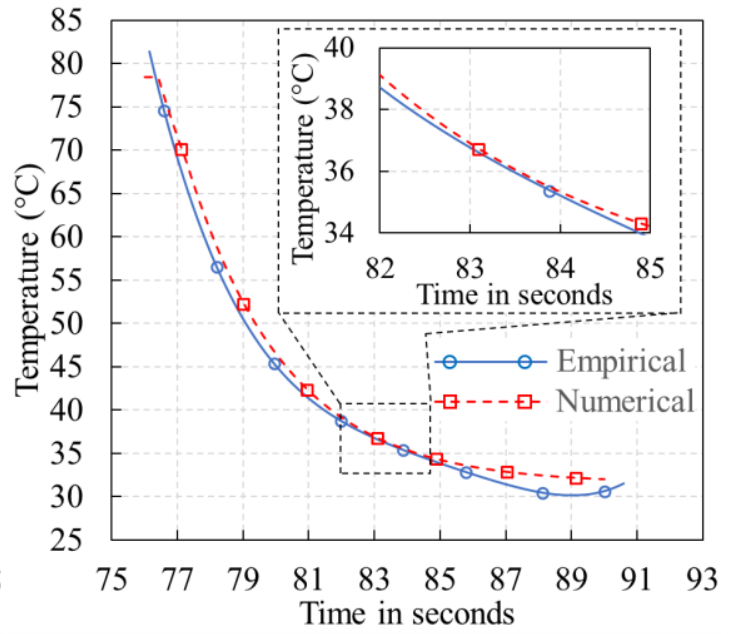

(b)

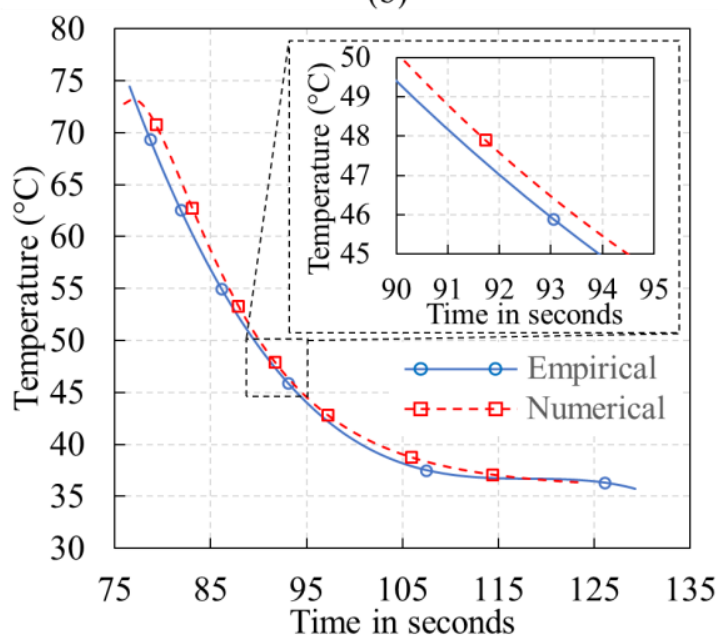

(d)

Fig. 15. Temperature variation with time obtained using our numerical model (SPH) and empirical equations at $V=0.70 \mathrm{~m} / \mathrm{s}, M H F=23 \mathrm{~kW} \cdot \mathrm{m}^{-2}$ and $W F T=0.8 \times 10^{-3} \mathrm{~m}$ : (a) P18; (b) P3; (c) P13; (d) P19. 


\section{Down-flowing water film}

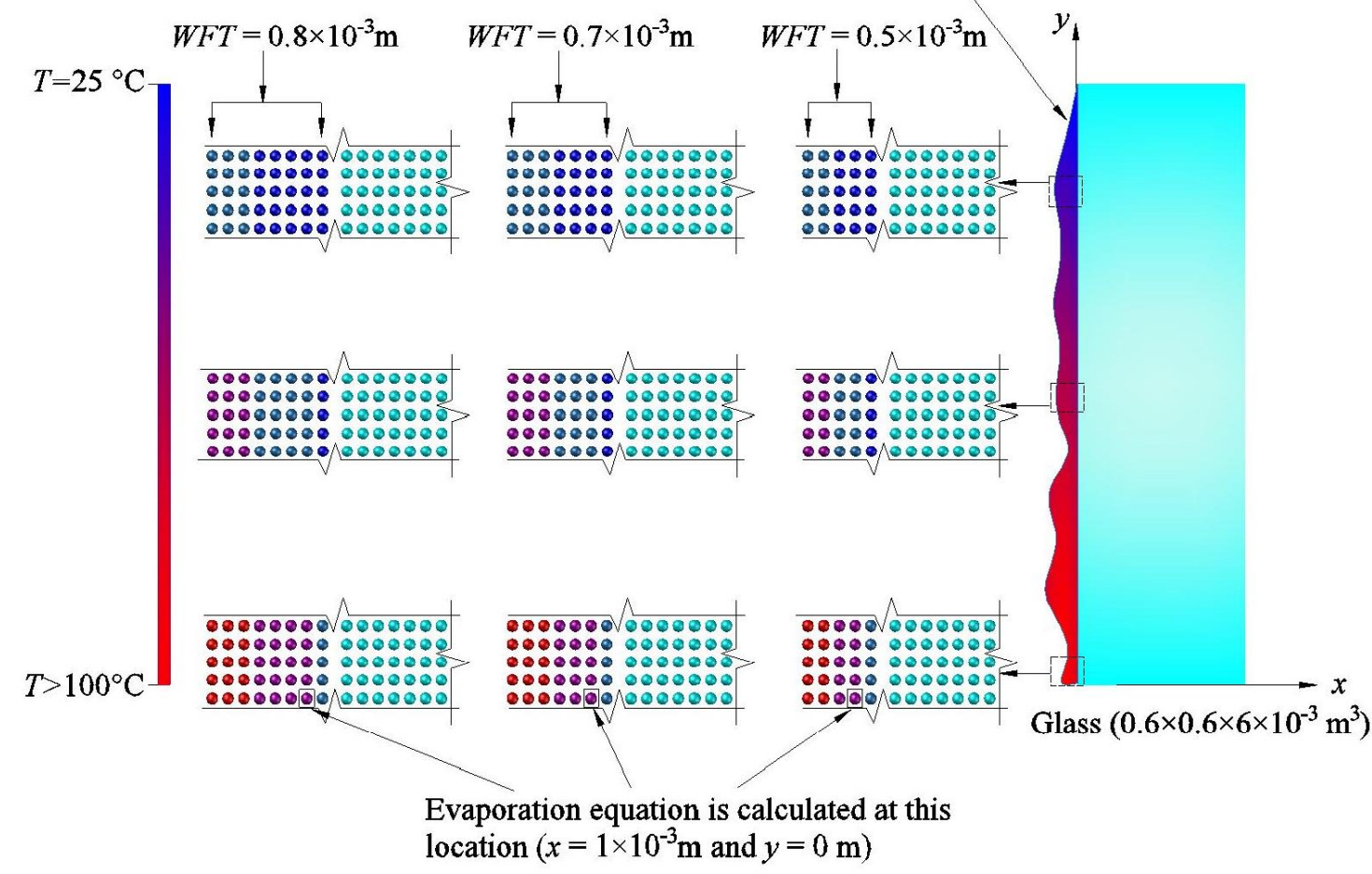

Fig. 16. Illustrative diagram shows the process and location of water evaporation calculation when $W F T=0.5 \times 10^{-3} \mathrm{~m}, W F T=0.7 \times 10^{-3} \mathrm{~m}$ and $W F T=0.8 \times 10^{-3} \mathrm{~m}$.

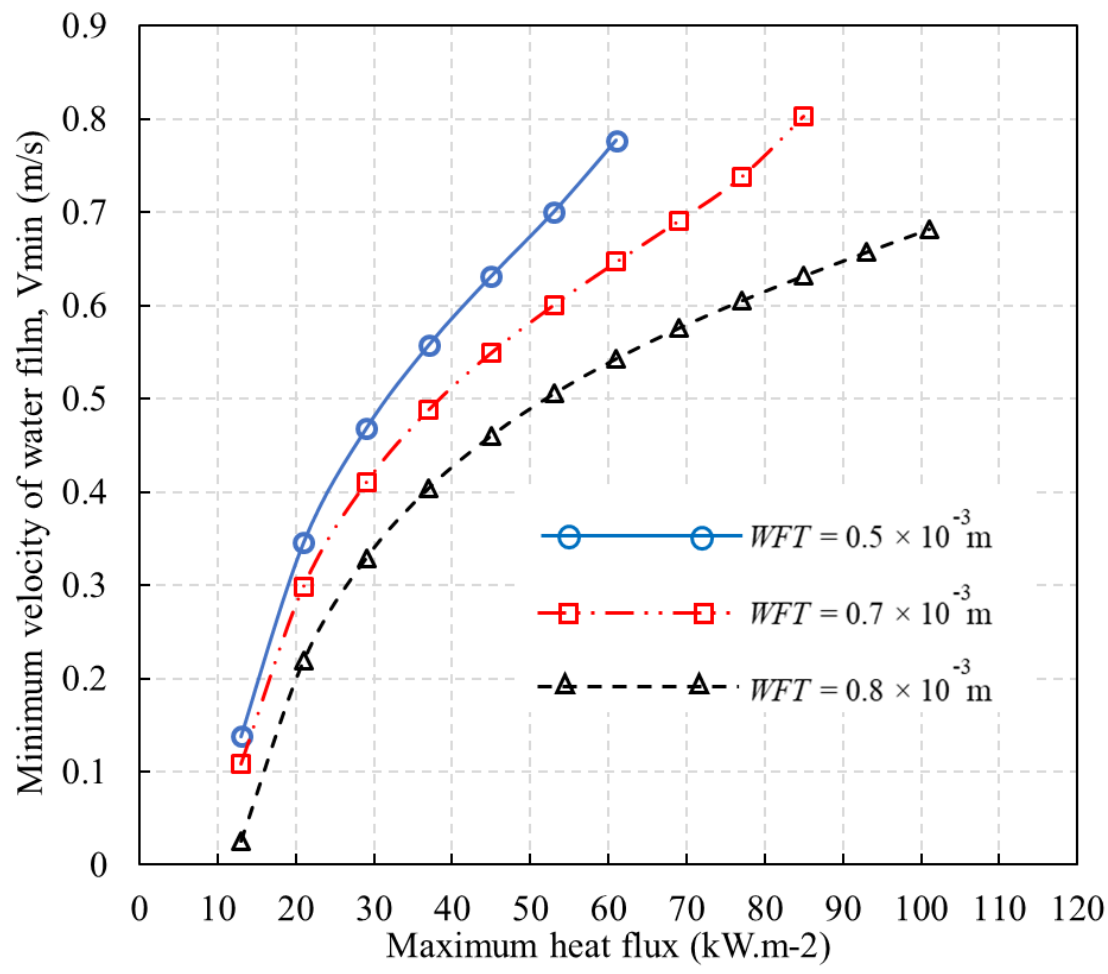

Fig. 17. Variation of minimum velocity of water film $\left(V_{\min }\right)$ to prevent evaporation with maximum heat flux $(M H F)$ at $W F T=0.5 \times 10^{-3} \mathrm{~m}, W F T=0.7 \times 10^{-3} \mathrm{~m}$ and $W F T=0.8$ $\times 10^{-3} \mathrm{~m}$. 
Table 1. The physical properties of glass and water.

\begin{tabular}{|c|c|c|c|c|}
\hline Material & Property & Symbol & Value & Unit \\
\hline \multirow[t]{5}{*}{ Glass } & Density & $\rho_{G}$ & 2500 & $\mathrm{~kg} / \mathrm{m}^{3}$ \\
\hline & Thermal conductivity & $K_{G}$ & 0.94 & $\mathrm{~W} / \mathrm{m} \cdot \mathrm{k}$ \\
\hline & Specific heat capacity & $C_{p G}$ & 820 & $\mathrm{~J} / \mathrm{kg} . \mathrm{k}$ \\
\hline & \multirow{2}{*}{$\begin{array}{l}\text { Thermal diffusivity } \\
\text { linear thermal expansion }\end{array}$} & $\alpha_{G}$ & $4.6 \times 10^{-7}$ & $\mathrm{~m}^{2} / \mathrm{s}$ \\
\hline & & $\beta$ & $9 \times 10^{-6}$ & ${ }^{\circ} \mathrm{C}^{-1}$ \\
\hline \multirow[t]{5}{*}{ Water } & Density & $\rho_{W}$ & 998 & $\mathrm{~kg} / \mathrm{m}^{3}$ \\
\hline & Thermal conductivity & $K_{W}$ & 0.6 & $\mathrm{~W} / \mathrm{m} \cdot \mathrm{k}$ \\
\hline & Specific heat capacity & $C_{p W}$ & 4182 & $\mathrm{~J} / \mathrm{kg} . \mathrm{K}$ \\
\hline & Thermal diffusivity & $\alpha_{W}$ & $1.43 \times 10^{-7}$ & $\mathrm{~m}^{2} / \mathrm{s}$ \\
\hline & Initial Temperature & $T$ & 25 & ${ }^{\circ} \mathrm{C}$ \\
\hline
\end{tabular}


Table 2. Temperature $T_{5}$ decrement in glass due to increased velocity and thickness of water film at different values of $M H F$ and $y$-coordinate.

\begin{tabular}{|c|c|c|c|c|}
\hline Case & $\begin{array}{l}y \text { - coordinate } \\
\text { (m) }\end{array}$ & $\begin{array}{l}M H F \\
\left(\mathrm{~kW} \cdot \mathrm{m}^{-2}\right)\end{array}$ & $\begin{array}{l}\text { Temperature } \\
\text { decrement } \\
\left({ }^{\circ} \mathrm{C}\right)\end{array}$ & $\begin{array}{l}\% \text { Increase of } \\
\text { water volume } \\
\text { flow rate per } 1 \\
{ }^{\circ} \mathrm{C} \text { decrement }\end{array}$ \\
\hline \multirow{15}{*}{$\begin{array}{l}\text { Increment of water } \\
\text { film thickness from }\end{array}$} & \multirow[t]{5}{*}{0.20} & 9.00 & 2.09 & 28.71 \\
\hline & & 12.00 & 2.81 & 21.35 \\
\hline & & 15.00 & 3.53 & 17.00 \\
\hline & & 18.00 & 4.25 & 14.12 \\
\hline & & 21.00 & 4.97 & 12.07 \\
\hline & \multirow[t]{5}{*}{0.30} & 9.00 & 1.64 & 36.59 \\
\hline & & 12.00 & 2.19 & 27.40 \\
\hline & & 15.00 & 2.74 & 21.90 \\
\hline & & 18.00 & 3.29 & 18.24 \\
\hline & & 21.00 & 3.85 & 15.58 \\
\hline & \multirow[t]{5}{*}{0.40} & 9.00 & 1.12 & 53.57 \\
\hline & & 12.00 & 1.51 & 39.74 \\
\hline & & 15.00 & 1.89 & 31.75 \\
\hline & & 18.00 & 2.28 & 26.32 \\
\hline & & 21.00 & 2.67 & 22.47 \\
\hline \multirow{15}{*}{$\begin{array}{l}\text { Increment of down- } \\
\text { flowing velocity } \\
\text { from } 0.3 \mathrm{~m} / \mathrm{s} \text { to } 1 \\
\mathrm{~m} / \mathrm{s}(233 \% \\
\text { increase in volume } \\
\text { flow rate) }\end{array}$} & \multirow[t]{5}{*}{0.20} & 9.00 & 12.82 & 18.17 \\
\hline & & 12.00 & 17.18 & 13.56 \\
\hline & & 15.00 & 21.54 & 10.82 \\
\hline & & 18.00 & 25.90 & 9.00 \\
\hline & & 21.00 & 30.27 & 7.70 \\
\hline & \multirow[t]{5}{*}{0.30} & 9.00 & 9.31 & 25.03 \\
\hline & & 12.00 & 12.48 & 18.67 \\
\hline & & 15.00 & 15.66 & 14.88 \\
\hline & & 18.00 & 18.83 & 12.37 \\
\hline & & 21.00 & 22.00 & 10.59 \\
\hline & \multirow[t]{5}{*}{0.40} & 9.00 & 5.48 & 42.52 \\
\hline & & 12.00 & 7.47 & 31.19 \\
\hline & & 15.00 & 9.46 & 24.63 \\
\hline & & 18.00 & 9.46 & 24.63 \\
\hline & & 21.00 & 13.44 & 17.34 \\
\hline
\end{tabular}

